Article

\title{
Analysis on the Characteristics of Dry and Wet Periods in The Yangtze River Basin
}

\author{
Hao Huang ${ }^{1} \mathbb{C}$, Bo Zhang ${ }^{1, *}$, Yanqiang Cui ${ }^{1}$ and Shangqian $\mathrm{Ma}^{2}$ \\ 1 College of Geography and Environmental Science, Northwest Normal University, Lanzhou 730070, China; \\ 2018212274@nwnu.edu.cn (H.H.); cyqyuzhong@163.com (Y.C.) \\ 2 College of Resources and Environmental Sciences, China Agricultural University, Beijing 100193, China; \\ msqnwnuedu@163.com \\ * Correspondence: zhangbo@nwnu.edu.cn
}

Received: 4 September 2020; Accepted: 15 October 2020; Published: 22 October 2020

\begin{abstract}
As China's main grain producing region, the Yangtze River basin is vulnerable to changes in wet and dry conditions. In this study, the monthly scale of standardized precipitation evapotranspiration index (SPEI) was calculated, based on the Penman-Monteith equation from 239 meteorological stations in the Yangtze River basin, from 1960 to 2017. Water regime characteristic areas of the Yangtze River basin were extracted and divided using the rotating empirical orthogonal function (REOF). The linear trend of the drought and wetness indicators, the abrupt changes of the rotated principal component time series (RPCs), and the change periods of the drought/wetness intensity (DI/WI) in each subregion were analyzed and discussed. Subsequently, the effects of El Niño-southern oscillation (ENSO) and arctic oscillation (AO) on drought and wetness events were discussed. The results showed that the Yangtze River basin has the characteristic of coexistence of drought and wetness, and drought and wetness of similar severity tend to occur in the same region. There were six subregions extracted through REOF, based on the monthly scale of SPEI, of which the northwestern pattern had an aridization tendency. The stations with significantly increased wetness were located in the middle and eastern basin. The stations in the south of the northwestern pattern, and the west of the southern pattern, had a tendency of wetting in the first 29 years, however, there has been a significant tendency of drying in this region in the last 29 years, which was caused by an abrupt change in 1994. In addition, other patterns had multiple abrupt changes, resulting in multiple transitions between dry and wet states. The principal periods of WI in the southern pattern and northern pattern were longer than the DI, but in other subregions DI was longer than WI. ENSO and AO had the most obvious influence on DI and WI. Compared with the cold phase of ENSO, the DI/WI in the warm phase were higher/lower; compared with the negative phase of $\mathrm{AO}$, both DI and WI were higher in the positive phase. The Hurst index showed that the current dry and wet conditions in the Yangtze River basin have persistent characteristics, the dry conditions in each subregion will continue in the future, and there were a few wetness indicators with weak anti-persistence.
\end{abstract}

Keywords: wetness and drought characteristics; SPEI; REOF; Yangtze River basin

\section{Introduction}

Climate warming has a profound impact on the global ecological environment. In the context of climate change, the pattern of water balance is changing [1-3], the surface evapotranspiration is increasing due to climate warming, and the uneven spatial and temporal distribution of interannual precipitation is strengthened, which leads to the increasing intensity and frequency of droughts, floods, and other disasters $[4,5]$. The response of drought and wetness changes in different regions to global warming is different. In the past 120 years, drought has increased in different parts of the United 
States, and the Great Plains of the United States have often been affected by drought $[6,7]$. In Italy, the climate has transformed to drought, and the precipitation has decreased by $0.47 \% \cdot \mathrm{a}^{-1}$ in the last 57 years [8]. The frequency of drought in countries in Oceania has reduced because of the influence of air circulation [9]. In China, the northwest region is relatively arid, and Lian et al. (2019) [10] found that precipitation amount and precipitation frequency in the western region of northwest China have both increased, while rainfall in the eastern region of northwest China has become more concentrated in the past 58 years, which confirmed the view that the northwest region is changing into a warmer and moister region [11]. Drought is aggravated due to the decrease in persistent precipitation, and the increase in days without precipitation in north China and southwest China [12]. In southern China, although persistent precipitation events and precipitation amount had an increasing trend, moderate and mild droughts often occurred [13], resulting in short-duration droughts, which also had an increasing tendency [14].

The Yangtze River basin is one of the two major basins, and also a major grain producing area in China. Owing to the influence of the monsoon, El Niño-southern oscillation (ENSO), and other factors, the Yangtze River basin has a frequent dry-wet conversion. In the Yangtze River basin, there was a severe flood in 2010, and a severe spring drought in 2011; the rainstorm and flood occurred on 7 December 2012, and a long summer drought occurred in 2013 [15-18]. The frequent dry-wet conversion brought numerous adverse effects to the ecosystem and agriculture, as well as challenges to monitoring [19].

Drought indexing is an important method to objectively quantify and compare the degree of dryness and wetness in regions with different climatic and hydrological conditions [20]. At present, there are three meteorological drought indexes: the palmer drought index (PDSI) [21], the standardized precipitation index (SPI) [22], and the standardized precipitation evapotranspiration index (SPEI) [23] that are widely used to monitor drought and wetness in the whole world, and different regions. PDSI has been effective in the monitoring and prediction of regional dry and wet conditions through the water balance model, which has achieved an important breakthrough in the drought index. However, it is difficult to compare the dry and wet states of different times and different regions; Mckee et al. (1993) proposed the SPI index, which can be used to monitor drought with multiple time scales. However, this model only takes precipitation into consideration, while ignoring the influence of water balance on regional dry and wet state, so the monitoring ability is not appropriate in the context of climate warming. Therefore, Vicente-Serrano et al. (2010) combined the water balance idea of PDSI and the multi-time scale idea of SPI to create the standardized precipitation evapotranspiration index (SPEI). Potential evapotranspiration has been added to SPEI, so that meteorological indicators, such as precipitation and temperature, are included in the drought evaluation system. Therefore, SPEI has been widely used in recent years. SPEI has good applicability in the monitoring of dry and wet conditions in China $[20,24]$, and is used to monitor the drought and wetness changes in agricultural areas, river basins, grasslands, and other regions [25-27].

The purpose of this study was to explore the changing characteristics of drought-wetness in the Yangtze River basin from 1960 to 2017, through the monthly scale SPEI. Due to the large area of the Yangtze River basin, REOF was used to divide the regions by different variation characteristics of wetness and drought. Subsequently, the trend of changes of drought and wetness indicators of meteorological stations and the RPCs, was used to reflect the dry and wet characteristics of each subregion in the Yangtze River basin. Finally, the influence of ENSO and arctic oscillation (AO) on drought and wetness events in the Yangtze River basin was analyzed through the generalized extreme value distribution (GEVD), and the continuity of the current variation trend into the future was explored through the Hurst index. 


\section{Study Area and Data}

\subsection{Study Area}

The Yangtze River basin $\left(90^{\circ} 33^{\prime} \mathrm{E} \sim 122^{\circ} 25^{\prime} \mathrm{E}, 24^{\circ} 30^{\prime} \mathrm{N} \sim 35^{\circ} 45^{\prime} \mathrm{N}\right)$ is the third largest basin in the world (Figure 1), and covers $18.8 \%$ of the land area, and one third of the total population, of China [28]. The Yangtze River basin has a large number of rivers and lakes, a developed economy, and rich resources. Within the basin, the Dongting Lake Plain, Yangtze River Delta Plain, Poyang Lake Plain, and Han River Plain are the main grain producing areas in China. Precipitation in the Yangtze River basin is greater in the southeast and less in the northwest, and the temperature is higher in the east and lower in the west. Within the basin, the Yunnan-Guizhou Plateau, Sichuan Basin, and Jinshajiang River Valley are closed, high-temperature areas under the influence of the topography [29]. The Yangtze River basin is vulnerable to drought and flood disasters. From 1961 to 1990, the losses caused by drought and flood disasters accounted for about $78 \%$ of the total losses, caused by meteorological disasters in the Yangtze River basin, while losses caused by drought alone were as high as 50\% [30].

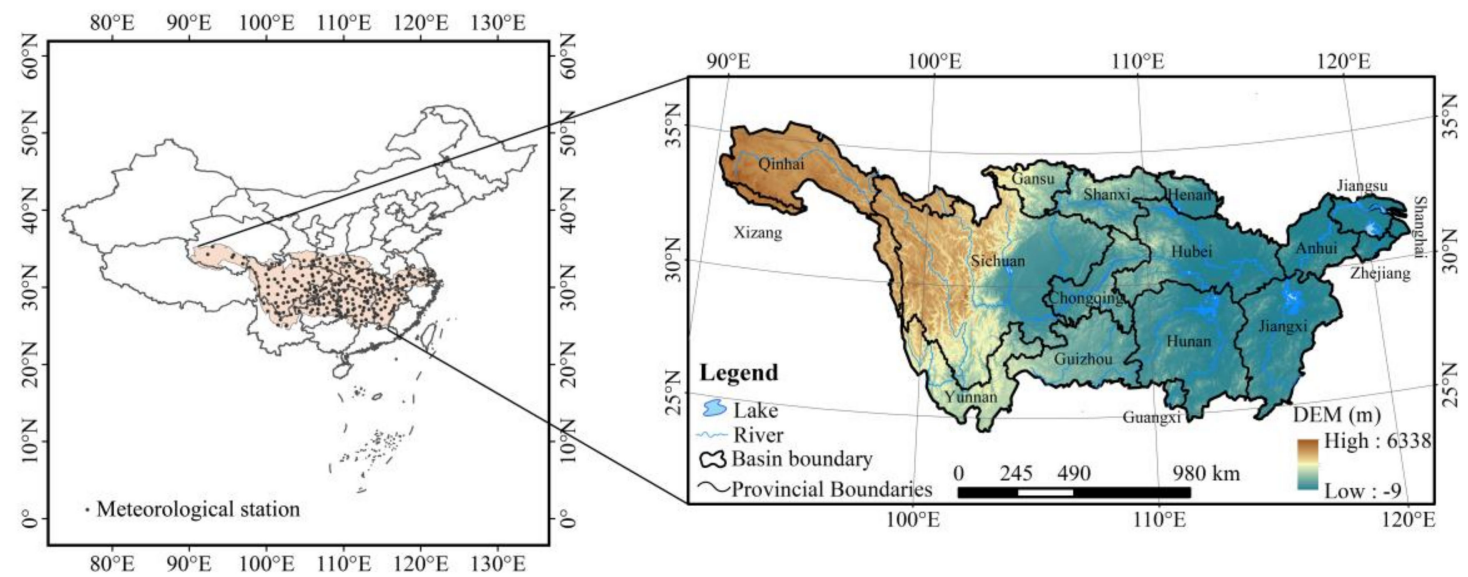

Figure 1. Digital elevation model and meteorological station distribution in the Yangtze River basin.

\subsection{Data Sources}

The daily wind speed $(\mathrm{m} / \mathrm{s})$, relative humidity $(\%)$, maximum temperature $\left({ }^{\circ} \mathrm{C}\right)$, sunshine time (h), daily rainfall (mm), the minimum temperature $\left({ }^{\circ} \mathrm{C}\right)$ data from 1961 to 2017, of 239 meteorological stations, in the Yangtze River basin were collected from the Chinese National Meteorological Information Center (http://data.cma.cn/site/index.html). The meteorological data quality was strictly controlled, while some data with missing measurements were interpolated by multiple regression. The data for ENSO and AO was sourced from the Climate Prediction Center (https://www.cpc.ncep.noaa.gov/).

\section{Method}

\subsection{Calculation of the Standardized Precipitation Evaporation Index}

The first step was to calculate potential evapotranspiration (PET), based on the Penman-Monteith equation, which was recommended by FAO-56 [31]:

$$
\mathrm{PET}=\frac{0.408 \Delta\left(R_{n}-G\right)+\gamma \frac{900}{T+273} u_{2}\left(e_{s}-e_{a}\right)}{\Delta+\gamma\left(1+0.34 u_{2}\right)}
$$

where PET is the monthly potential evapotranspiration $\left(\mathrm{mm} \mathrm{day}^{-1}\right) ; R_{n}$ is the net radiation $\left(\mathrm{MJ} \mathrm{m}^{-2}\right.$ day $\left.^{-1}\right) ; G$ is the soil heat flux density $\left(\mathrm{MJ} \mathrm{m}^{-2}\right.$ day $\left.{ }^{-1}\right) ; \gamma$ is the psychrometric constant $\left(\mathrm{kPa}^{\circ} \mathrm{C}^{-1}\right) ; u_{2}$ is the wind speed at $2 \mathrm{~m}$ height $\left(\mathrm{m} \mathrm{s}^{-1}\right) ; T$ is the mean monthly temperature $\left({ }^{\circ} \mathrm{C}\right) ; \Delta$ is slope vapor pressure curve $\left(\mathrm{kPa}{ }^{\circ} \mathrm{C}^{-1}\right) ; e_{a}$ is the actual vapor pressure $(\mathrm{kPa})$; and $e_{s}$ is the saturation vapor pressure $(\mathrm{kPa})$. 
The second step was to calculate the difference between monthly precipitation and potential evapotranspiration:

$$
D_{i}=P_{i}-P E T_{i}
$$

where $P_{i}$ is the monthly precipitation, and $P E T_{i}$ is the monthly potential evapotranspiration.

The third step was to simulate the water equilibrium accumulated probabilities, through the three-parameter log-logistic probability distribution [32]:

$$
\begin{gathered}
f(x)=\frac{\beta}{\alpha}\left(\frac{x-\gamma}{\alpha}\right)^{\beta-1}\left[1+\left(\frac{x-\gamma}{\alpha}\right)^{\beta-2}\right]^{-2} \\
F(x)=\left[1+\left(\frac{\alpha}{x-\gamma}\right)^{\beta}\right]^{-1}
\end{gathered}
$$

where $f(x)$ is the probability density function of a three-parameter log-logistic distributed variable, and $F(x)$ is the probability distribution function of the $D_{i}$ series, according to the log-logistic distribution. $\alpha, \beta$, and $\gamma$ are scale, shape, and origin parameters, respectively, for $D_{i}$ values in the range $(\mathrm{g}<x<\infty)$. They can be determined by using the L-moment method [32]:

$$
\begin{gathered}
\beta=\frac{2 \mathrm{w}_{1}-\mathrm{w}_{0}}{6 \mathrm{w}_{1}-\mathrm{w}_{0}-6 \mathrm{w}_{2}} \\
\alpha=\frac{\left(\mathrm{w}_{0}-2 \mathrm{w}_{1}\right) \beta}{\Gamma\left(1+\frac{1}{\beta}\right) \Gamma\left(1-\frac{1}{\beta}\right)} \\
\gamma=\mathrm{w}_{0}-\alpha \Gamma\left(1+\frac{1}{\beta}\right) \Gamma\left(1-\frac{1}{\beta}\right)
\end{gathered}
$$

where $\Gamma(\beta)$ is the gamma function of $\beta . \mathrm{w}_{\mathrm{s}}(\mathrm{s}=0,1,2 \ldots)$ can be calculated by the probability weighted moments, through the L-moment method [33]:

$$
\mathrm{w}_{s}=\frac{1}{n} \sum_{i=1}^{n}\left(1-\frac{i-0.35}{n}\right)^{s} D_{i}
$$

where $n$ is the sample size of $D_{i}$.

The fourth step was to process the sequence with standard normal distribution. First, the cumulative probability density was standardized [23]:

$$
P=1-F(x)
$$

When the cumulative probability $P \leq 0.5$ :

$$
\begin{gathered}
\omega=\sqrt{-2 \ln (P)} \\
\text { SPEI }=\omega-\frac{c_{0}+c_{1} \omega+c_{2} \omega^{2}}{1+d_{1} \omega+d_{2} \omega^{2}+d_{3} \omega^{3}}
\end{gathered}
$$

where $c_{0}=2.515517, c_{1}=0.802853, c_{2}=0.010328, d_{1}=1.432788, d_{2}=0.189269, d_{3}=0.001308$. When $P>0.5$, $\omega=\sqrt{-2 \ln (1-P)}$ and the sign of the resultant SPEI is reversed [34-36]. Then, the magnitude of drought and wetness can be seen in Table 1: 
Table 1. Classifications of drought and wetness magnitude based on standardized precipitation evapotranspiration index (SPEI) value.

\begin{tabular}{cccc}
\hline Mild Drought & Moderate Drought & Severe Drought & Extreme Drought \\
\hline$-1<\mathrm{SPEI} \leq-0.5$ & $-1.5<\mathrm{SPEI} \leq-1$ & $-2<\mathrm{SPEI} \leq-1.5$ & $\mathrm{SPEI} \leq-2$ \\
\hline Mild Wetness & Moderate Wetness & Severe Wetness & Extreme Wetness \\
\hline $1>\mathrm{SPEI} \geq 0.5$ & $1.5>\mathrm{SPEI} \geq 1$ & $2>\mathrm{SPEI} \geq 1.5$ & $\mathrm{SPEI} \geq 2$ \\
\hline
\end{tabular}

\subsection{Empirical Orthogonal Function (EOF) and Rotational Empirical Orthogonal Function (REOF)}

In order to avoid data being smoothed, it is better to conduct partition analysis when studying large areas. Due to the fact that the empirical orthogonal function (EOF) does not have a fixed base function, it is convenient to decompose the space-time field of complex meteorological element fields. The decomposed eigenvectors are orthogonal to each other, and the information of the variable field is generally concentrated in the first few patterns. Therefore, the changes in the spatio-temporal field of meteorological elements can be reflected by the first few patterns, where the cumulative variance reaches a certain level. EOF expresses the space-time field of the weather variable through a matrix [37]:

$$
X_{m \times n}=\left[\begin{array}{cccccc}
x_{11} & x_{12} & \ldots & x_{1 j} & \ldots & x_{1 n} \\
x_{21} & x_{22} & \ldots & x_{2 j} & \ldots & x_{2 n} \\
\ldots & \ldots & & \ldots & & \ldots \\
x_{i 1} & x_{i 2} & \ldots & x_{i j} & \ldots & x_{i n} \\
\ldots & \ldots & & \ldots & & \ldots \\
x_{m 1} & x_{m 2} & \ldots & x_{m j} & \ldots & x_{m n}
\end{array}\right]
$$

where $m$ is the point in space, which can be an observation station or a grid point. $n$ is the point in time, which represents the number of observations. $x_{i j}$ is the $j$ th observation value at the $i$ th meteorological station or grid point. And $X_{m \times n}$ can be seen as a linear combination of $k$ spatial feature vectors and corresponding time weight series:

$$
X_{m \times n}=V_{m \times k} \cdot T_{k \times n}
$$

where $V$ is the space matrix, also known as spatial patterns, and $T$ is the time series matrix. Through this process, the spatial typical field and time series of the month scale SPEI were extracted.

The rotating empirical orthogonal function (REOF) rotates the original matrix greatly, on the basis of EOF decomposition, so that the high load vector field of the same spatial patterns are concentrated in the region of a few variables, and the remaining load of other regions are close to 0 . In this way, the clarity of the feature field space and the stability of time are increased, which is conducive to the extraction of local features of the spatial distribution of climate elements [38-40], resulting in the same region having internal similarities, and differences between different regions. More information about REOF analysis can be found in the review papers of Richman (1986) [41] and Hannachi et al. (2007) [42]. In this study, the variable of REOF is the monthly scale SPEI value arranged in temporal and spatial order.

\section{3. "Take the Minimum" Category}

When the spatial vector after REOF is $\geq 0.3$, assign each meteorological station to the modal ordinal number of each mode; otherwise, assign a specific value (the specific value must be greater than the modal ordinal number, 9 was selected in this study):

$$
\left\{\begin{array}{l}
C V_{i j}=i, V_{i j} \geq 0.3 \\
C V_{i j}=9, V_{i j}<0.3
\end{array}\right.
$$

where $C V_{i j}$ is the classification value of the $\mathrm{j}$ meteorological station of the $i$ spatial vector. $V_{i j}$ is the spatial vector value of the $j$ meteorological station of the $i$ spatial vector, $i=1,2,3, \ldots, 6$. The minimum 
classification value of $C V_{i j}$ is the final classification value [43], the purpose of which is to extract the maximum absolute spatial load of all patterns of each meteorological station, and find out the number of the pattern where the maximum absolute spatial load is located. The aggregate regions of each pattern can be extracted into a composite region, and the month scale SPEI patterns can be partitioned:

$$
C_{j}=\min \left\{C V_{1 j}, C V_{2 j}, C V_{3 j}, \ldots, C V_{6 j}\right\}
$$

\subsection{Linear Trend Rate and Significance Calculation of Drought and Wetness Index}

The drought and wetness indicator of the sample amount, $n$, is represented by $Y, t$ is the corresponding year, and the simple linear regression equation is calculated by fitting the least squares method [44]:

$$
Y=a t+b \quad(t=1,2, \cdots, n)
$$

where $a$ is the regression coefficient, 10 times of which is taken as the drought and wetness indicator tendency rate, and the significance of the variation trend is tested by the Mann-Kendall non-parametric test method [45].

\subsection{Definition of Drought and Wetness Events}

In this study, the process of SPEI values being continuously $\leq-0.5$ was defined as a drought event, and the process of SPEI values being continuously $\geq 0.5$ was defined as a wetness event. The OTD and OTW are the occurrence times of drought and wetness events. The absolute value of the cumulative value of the SPEI value between these procedures, were the drought intensity (DI) and wetness intensity (WI). The DD and WD are the duration of drought and wetness events.

\subsection{Other Methods}

The Mann-Kendal (M-K) abrupt test $[46,47]$ is generally used for climate abrupt detection. UF and UB (forward and backward of the sequential values of the statistic U, see, e.g., Yang, Y.; and Tian, F., 2009 [48]) are used for time series analysis when UF $>0$ or $<0$, the sequence shows a trend of increase/decrease, and the curve UF exceeds the reliability line $(P<0.05)$, indicating a significant trend of change. If the intersection of UF and UB is located between the reliability lines, this point is the beginning of the abrupt transition. In this study, the M-K abrupt test was used to detect the abruptness of the rotated principal component time series (RPCs).

$\mathrm{R} / \mathrm{S}$ analysis (rescaled range analysis) is a nonlinear scientific prediction method, which has good applicability to both normal distribution and non-normal distribution time series data. The Hurst index has a value interval of $[0,1]$. When $\mathrm{H}>0.5$, the future trend is consistent with the past. When $\mathrm{H}<0.5$, it indicates that the future trend is contrary to the past, and the process has anti-persistence, andthe closer $\mathrm{H}$ is to 0 , the stronger the anti-persistence will be [49].

The generalized extreme value distribution (GEVD) is a continuous probability distribution based on extreme value theory. The advantage of GEVD is that the probability density function (PDF) can be estimated without making any assumptions about the unknown distribution. Moreover, GEVD has good flexibility in dealing with the tails of different types of distributions [50], and can be well used for the description of meteorological elements. In this study, GEVD was used to show the distribution of OTD, DI, DD, OTW, WI, and WD, when ENSO is in a cold/warm phase, and AO is in a positive/negative phase.

In this study, the Pearson correlation analysis method [51] was used to analyze the correlation between SPEI of the central load of each pattern and the RPCs, and the moving average method [37] was used to show the phased state of the central load SPEI value. Morlet wavelet variance [52] was used to identify DI and WI cycles. The inverse distance weight method (IDW) [53] was used as the spatial interpolation method in this study. 


\section{Results}

4.1. Spatial Distribution of the Number of Dry/Wet Months and Drought/Wetness Events in the Yangtze River Basin

Figure 2 shows the spatial distribution of the number of dry and wet months in the Yangtze River basin. The number of dry and wet months (Figure 2(a1,a2)) in the middle and lower reaches of the Yangtze River was more than that in the upper reaches, especially in Hunan, Jiangxi, and Anhui. The distribution characteristics of mild drought and mild wet (Figure 2(b1,b2)), moderate drought, and moderate wet months (Figure 2(c1,c2)) were similar to the overall distribution characteristics (Figure 2(a1,a2)). Therefore, the Yangtze River basin mainly experienced mild and moderate drought and wetness.
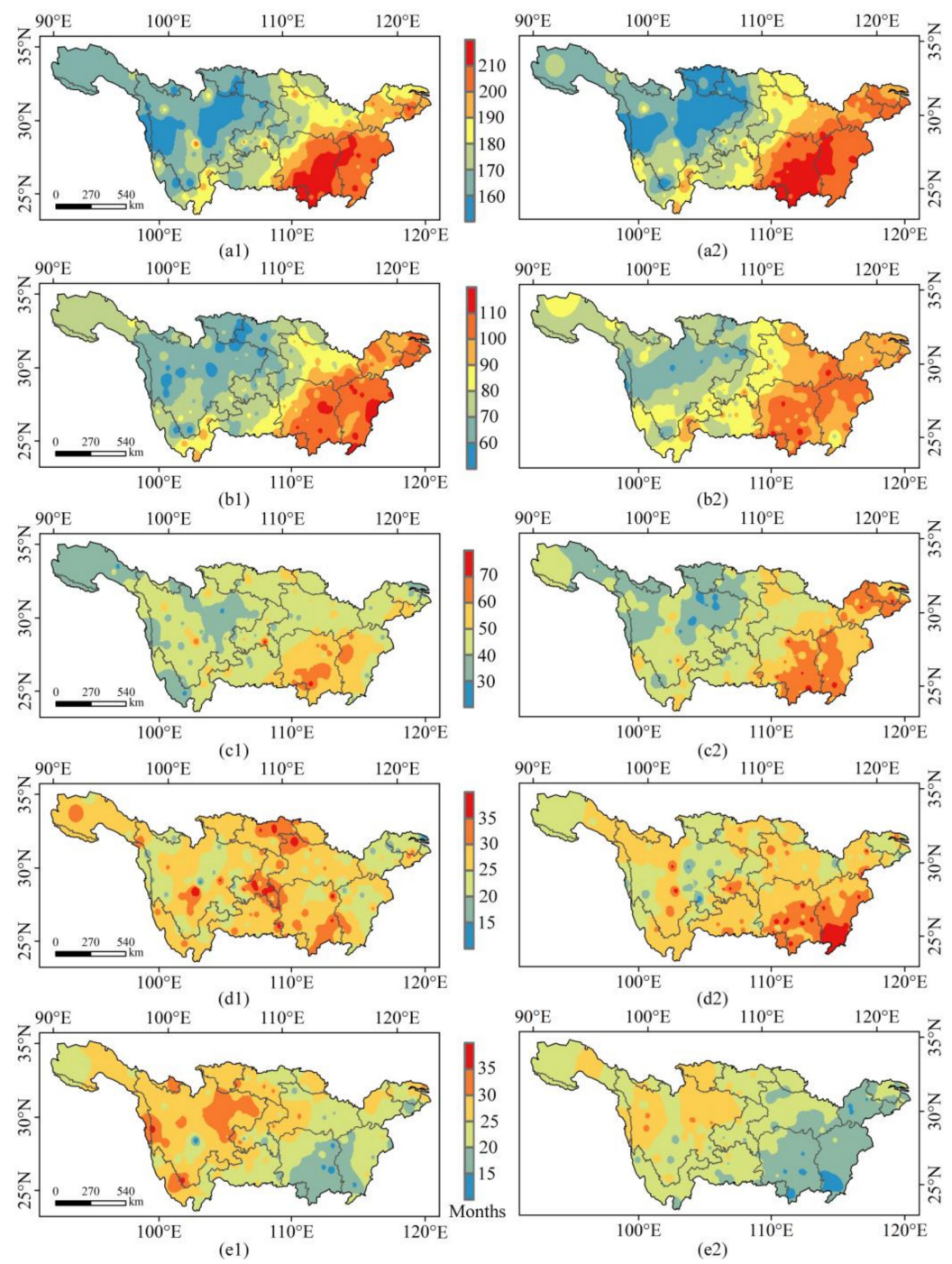

Figure 2. The spatial distribution of (a1) all dry months, (a2) all wet months, and the months with the magnitude of (b1) mild drought, (b2) mild wetness, (c1) moderate drought, (c2) moderate wetness, (d1) severe drought, (d2) severe wetness, (e1) extreme drought, and (e2) extreme wetness.

Areas with more than 25 severely dry and wet months are widely distributed in the whole basin (Figure $2(\mathrm{~d} 1, \mathrm{~d} 2))$, indicating that the probability of severe drought and wetness events in the whole basin was relatively close. For extreme dry and wet months (Figure 2(e1,e2)), although the overall frequency of months was relatively small, the relatively frequent occurrences were mainly located in the upper reaches of the Yangtze River, with relatively few occurrences in the middle and lower 
reaches of the Yangtze River. Furthermore, Figure 3 shows that short duration events occurred in the middle and lower reaches of the Yangtze River, while long duration events occurred in central and eastern Sichuan, southern Chongqing, and northern Yunnan, which also explained the coexistence of drought and wetness in the Yangtze River basin. However, Figure 3 shows that there are more drought and wetness events with short duration occurring in the Yangtze River basin.
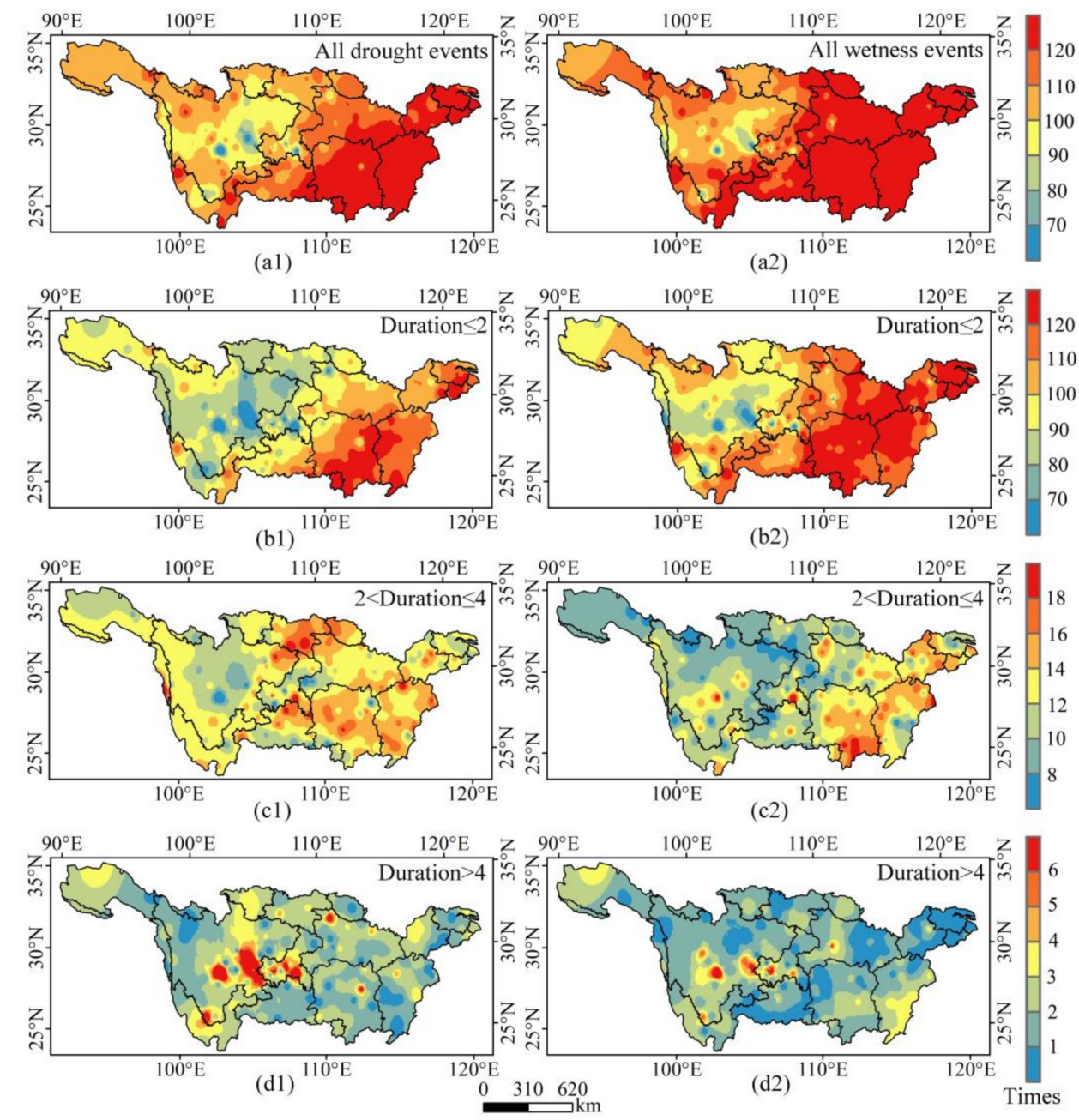

(c2)

Figure 3. Spatial distribution of the occurrence times of drought (OTD) and occurrence times of wetness (OTW) with different durations. 1 is the spatial distribution of OTD; 2 is the spatial distribution of OTW; (a) is all drought-wetness events, and (b-d) are OTD/OTW with different durations.

\subsection{Partitioning Based on REOF}

The monthly SPEI values of the Yangtze River basin from 1960 to 2017 were decomposed by REOF, and the patterns that reached significance level were screened by the North criterion [54] (Table 2). Six of the first seven consecutive patterns had reached a significant level $(P<0.05)$, and the cumulative variance contribution rate of the first six patterns reached $54.27 \%$, which best represented the distribution structure of the drought and wetness variable field in the Yangtze River basin. 
Table 2. 1960-2017 contribution rate and cumulative contribution rate of rotating empirical orthogonal function (REOF) patterns.

\begin{tabular}{cccccccc}
\hline Pattern & REOF1 & REOF2 & REOF3 & REOF4 & REOF5 & REOF6 & REOF7 \\
\hline Contribution rate & $21.99 \%$ & $11.59 \%$ & $8.23 \%$ & $5.08 \%$ & $4.50 \%$ & $2.89 \%$ & $2.54 \%$ \\
Cumulative contribution rate & $21.99 \%$ & $33.58 \%$ & $41.81 \%$ & $46.89 \%$ & $51.39 \%$ & $54.27 \%$ & $56.81 \%$ \\
Is it significant? & Yes & Yes & Yes & Yes & Yes & Yes & No \\
\hline
\end{tabular}

The EOF eigenvectors of the first six significant patterns were orthogonally rotated, so that the loads with similar change characteristics could be gathered in space. IDW spatial interpolation of the rotated load (Figure 4) shows that the high positive value of load in pattern 1 is higher than the absolute value of the high negative value, and the central load (the load with the highest absolute value) is located in the east of the Yangtze River basin (Figure 4a), so pattern 1 can be named as the eastern pattern (Table 3). The high positive load value region of pattern 2 is located in the southeast of the Yangtze River basin, and the central load of the pattern is located in the southeast of the Yangtze River basin. Therefore, pattern 2 can be called the Southeastern pattern (Figure 4b). Similarly, patterns 3,5, and 6 can be called the Southern, Southwestern, and Northwestern patterns, respectively. The difference is that the high negative load value of pattern 4 is higher than the high positive load value. The central load is located in the northern part of the Yangtze River basin, where the high negative load value is located, therefore, this pattern can be called the northern pattern (Figure $4 \mathrm{~d}$ ).
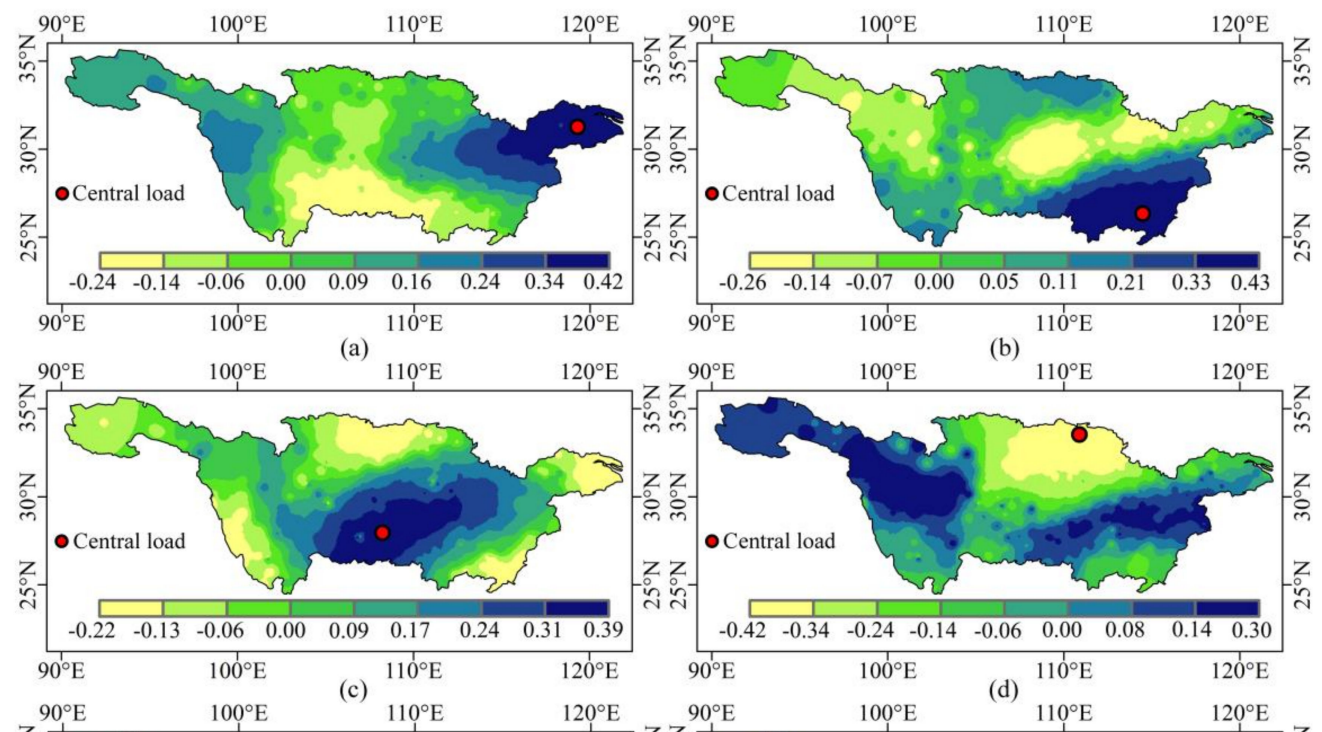

(b)
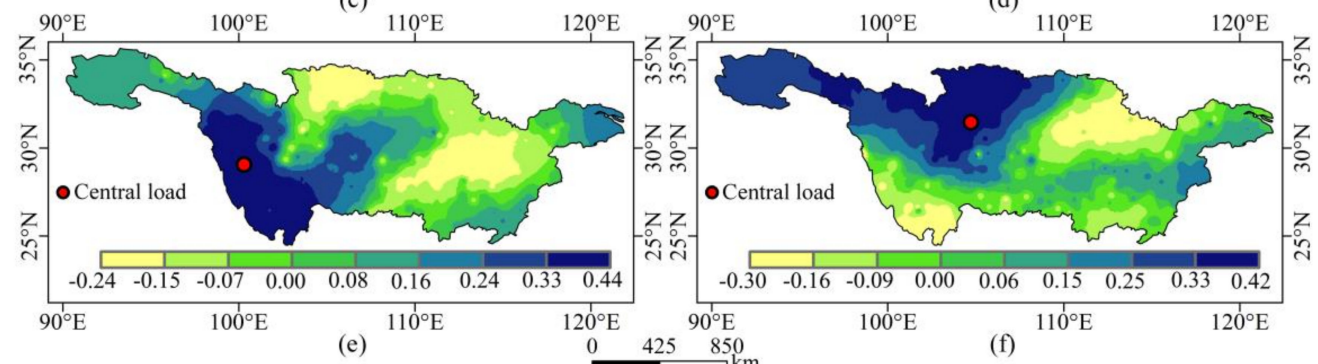

(e)

\begin{tabular}{lll}
0 & 425 & 850 \\
\hline
\end{tabular} $100^{\circ} \mathrm{E}$

(d) $110^{\circ} \mathrm{E}$

Figure 4. Distribution of the space load value and central load of the significant pattern in (a) REOF1, (b) REOF2, (c) REOF3; (d) REOF4, (e) REOF5, and (f) REOF6. 
Table 3. Information of the patterns.

\begin{tabular}{cccc}
\hline Pattern & REOF1 & REOF2 & REOF3 \\
\hline Name & The Eastern Pattern & The Southeastern Pattern & The Southern Pattern \\
Subregion I & Subregion II & Subregion III \\
Representative region & St896 & 57731 \\
Representative station & 58345 & REOF5 & REOF6 \\
\hline Pattern & REOF4 & The Southeastern pattern & The Northwestern pattern \\
Name & The Northern pattern & Subregion VI \\
Representative region & Subregion IV & 56537 & 56196 \\
Representative station & 57154 & & \\
\hline
\end{tabular}

Figure 5 shows the classification of meteorological stations, as well as the results of regional division and extraction. The clustering and screening of meteorological stations by the "Take the minimum" classification method showed that only eight meteorological stations had a poor aggregation effect, and $96.65 \%$ of meteorological stations had a good aggregation effect (Figure 5a). The control range of the meteorological stations was constructed through the Tyson polygon, and the space loads were extracted according to the classification (Figure $5 b$ ). The eastern stations are located in the high positive value region of pattern 1 (Figure 4), and the southeastern stations are located in the high positive value region of pattern 2 . The southern, southwestern, and northwestern subregions are mainly located in the high positive value regions of patterns 3,5 , and 6 . The stations classified as " 9 " are located in the high negative value region of pattern 4 , and part of the high positive value region of pattern 6, which is located on the Qinghai-Tibet Plateau. Therefore, taking into account the continuity of the region, the Yangtze River basin was divided into six subregions (Figure 5, Table 3).
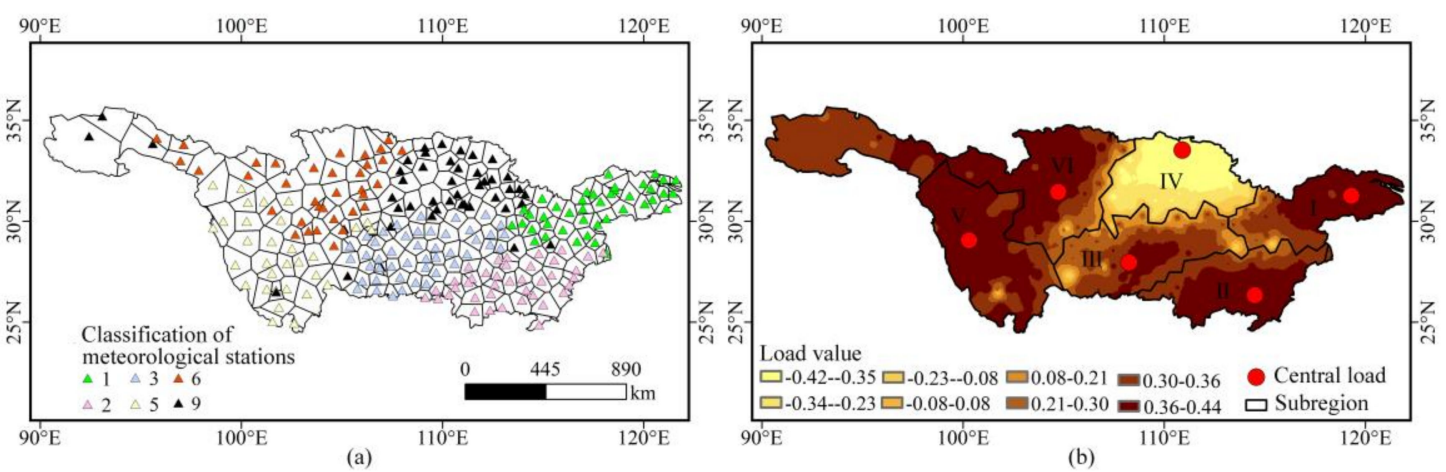

Figure 5. The spatial distribution of (a) the Tyson polygon classification of meteorological stations, and (b) classified load value and feature area extraction.

\subsection{Change Characteristics of Drought and Wetness}

The spatial difference of the load after REOF reflects that the regions where they locate have different development directions in time. Therefore, the change of RPCs and the central load SPEI value can be used to analyze the variation in the drought and wetness of different subregions in the Yangtze River basin change characteristics. The combination of the spatial load and the RPCs can reflect the temporal and spatial variation characteristics of drought and wetness in the Yangtze River basin. The positive or negative spatial load indicates that the dry or wet conditions in different regions have different changing directions [37]. If the load value of the high-load region is positive, a negative value of the time series reflects that the region is in a dry state, and a positive value of the time series reflects that the region is in a wet state. If the load value of the region is negative, when the value of the time series is positive, the region is in a dry state, and when the value of the time series is negative, the area is in a wet state. From Table 4, it can be seen that the RPCs 1, 2, 3, 5, and 6 have significant positive correlation with the SPEI value of the central load meteorological stations, and the RPC 4 has a significant negative correlation with the SPEI value of the central load meteorological station, which reflects the above description. Since the time series and the SPEI value of the central load have a 
significant correlation, the change in the SPEI value of the central load and RPCs can be used to reflect the characteristics of drought and wetness changes in subregions.

Table 4. Correlation between the rotated principal components (RPCs) and SPEI value of the central load of meteorological stations.

\begin{tabular}{ccccccc}
\hline Pattern & REOF1 & REOF2 & REOF3 & REOF4 & REOF5 & REOF6 \\
\hline Station & 58345 & 57896 & 57731 & 57154 & 56357 & 56196 \\
correlation coefficient & 0.83 & 0.78 & 0.72 & -0.79 & 0.65 & 0.6 \\
Significant level & $* * *$ & $* * *$ & $* * *$ & $* * *$ & $* * *$ & $* * *$ \\
\hline
\end{tabular}

Note: ${ }^{*}$ is $P<0.05,{ }^{* *}$ is $P<0.01,{ }^{* * *}$ is $P<0.001$, the same below.

\subsubsection{Distribution of Conditions of Drought and Wetness in Each Year-Month}

Figure 6 shows the year-month distribution characteristics of the SPEI values of the central load meteorological stations of the REOF significant patterns in the Yangtze River Basin from 1960 to 2017. Drought in subregion I-V mainly occurred from April to November (Figure 6), and the higher magnitude droughts mainly occurred from May to September. Although the distribution of wet months was wider than that of dry months, the months with higher wetness magnitude still mainly occurred from May to September. Generally speaking, subregion VI was more arid than the other subregions, and extreme drought was prone to occur from May to October.
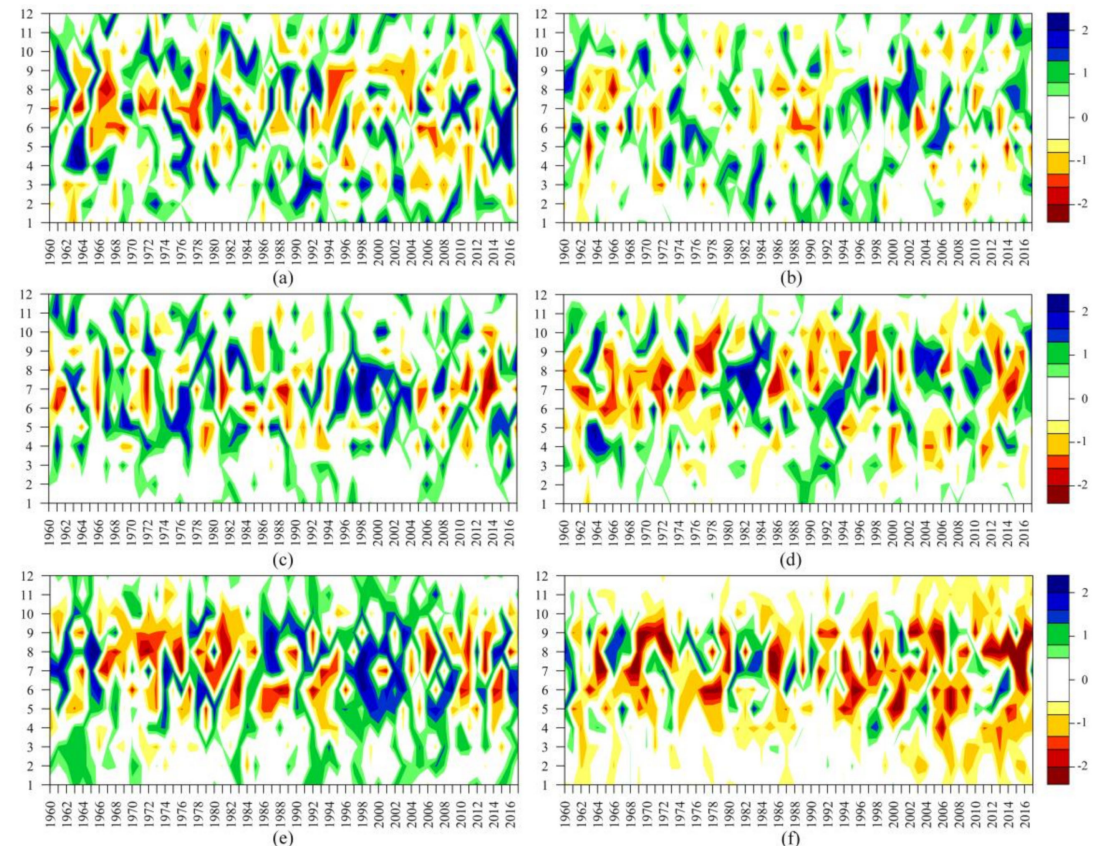

Figure 6. Year-month distribution of SPEI values of the central load meteorological stations in (a) subregion I, (b) subregion II, (c) subregion III, (d) subregion IV, (e) subregion V, and (f) subregion VI.

The alternating distribution of wet and dry months in subregion I fluctuated slightly, indicating that the dry and wet state of the region was relatively stable (Figure 6a). Subregion II had more normal months in all subregions, and extreme dry and wet months were the least in the all subregions (Figure 6b). There were more wet months than dry months in subregion III, where extremely wet months were more likely to occur than extremely dry months, and from 1994 to 2004 there was a long period of wet state in this region (Figure 6c). The subregion IV was in a dry state from May to September before 1979, and then changed to a state of alternating drought and wetness (Figure 6d). There were more dry months from 1966 to 1985, and there were more wet months from 1996 to 2009 , in subregion V (Figure 6e). Subregion VI had more dry months and fewer wet months; after 1994, 
the dry months expanded, and the months with higher drought magnitude also increased, indicating that the region faced an increasing risk of drought (Figure 6f).

\subsubsection{Change Trend of Drought and Wetness Indicators}

Table 5 shows the linear trend of the drought and wetness indicators in the Yangtze River basin from 1960 to 2017. For drought indicators, the occurrence times of drought events (OTD) in subregion IV had decreased significantly $(P<0.05)$, and the dry months in subregion VI had increased significantly. For the wetness indicators, the WI increased significantly $(P<0.05)$ in subregion IV, the wet months increased significantly in subregion $\mathrm{V}$, but the wet months and the occurrence times of wetness events (OTW) decreased significantly in subregion VI. Based on the comparison of drought and wetness indicators, among all the subregions, only subregion VI can be determined to be in obvious aridification.

Table 5. The 1960-2017 linear trend of drought and wetness indicators in The Yangtze River basin.

\begin{tabular}{ccccc}
\hline Station & Dry Months & OTD & DD & DI \\
\hline 58345 & -0.093 & -0.027 & 0.008 & -0.055 \\
57896 & -0.162 & -0.090 & -0.098 & -0.104 \\
57731 & 0.009 & 0.002 & 0.008 & 0.004 \\
57154 & -0.178 & $-\mathbf{0 . 1 5 3}$ & -0.016 & 0.041 \\
56357 & -0.129 & -0.048 & -0.038 & 0.047 \\
56196 & 0.287 & 0.078 & 0.152 & 0.242 \\
\hline Station & Moist Months & $\mathbf{O T W}$ & $\mathbf{W D}$ & WI \\
\hline 58345 & -0.005 & -0.024 & 0.023 & 0.097 \\
57896 & 0.122 & -0.017 & 0.044 & 0.048 \\
57731 & -0.039 & -0.008 & 0.001 & 0.007 \\
57154 & 0.105 & 0.009 & 0.115 & $\mathbf{0 . 1 9 8}$ \\
56357 & $\mathbf{0 . 2 4 7}$ & 0.103 & 0.084 & 0.040 \\
56196 & $\mathbf{- 0 . 2 8 0}$ & $\mathbf{- 0 . 1 3 8}$ & -0.048 & -0.050 \\
\hline
\end{tabular}

Note: Bold font means $P<0.05$.

As a whole, there are just a few drought and wetness indicators in each subregion with a significant change trend. On the one hand, for the long-term change tendency, the drought-wetness transition in subregions 1-3 had smaller fluctuations than subregions 4-6 (Figure 6). Therefore, the OTD and OTW, the wet and dry months, the duration of drought events (DD), and the duration of wetness events (WD), the drought intensity (DI), and the wetness intensity (WI) did not reach the significance level $(P>0.05)$ in subregions $1-3$. On the other hand, there were fewer meteorological stations with a significant increasing trend in subregions 1-3 (Figure 7).

Figure 7 shows the spatial distribution of changing tendency from 1960 to 2017. In terms of the occurrence times, the OTD increased significantly (Figure 7(a1)), and the OTW decreased significantly (Figure 7(b1)), in the western part of subregion III and the southern part of subregion VI, indicating that this region is gradually becoming arid. In other subregions, except for the OTD in the southern part of subregion I that showed a significant decreasing trend, both the OTD and OTW were on an increasing trend, leading to more frequent droughts and floods (Figure 6).

As for the intensity, the DI of subregions I, II, IV, and the west of subregion V was weakened (Figure 7(a2)), while the WI increased (Figure 7(b2)), showing a tendency of wetting. However, the western part of subregion III and the central and southern parts of subregion VI both showed a trend of aridification, with decreasing WI and increasing DI. The DD and WD (Figure 7(a3,b3)) were consistent with the situation reflected by the DI and WI. 

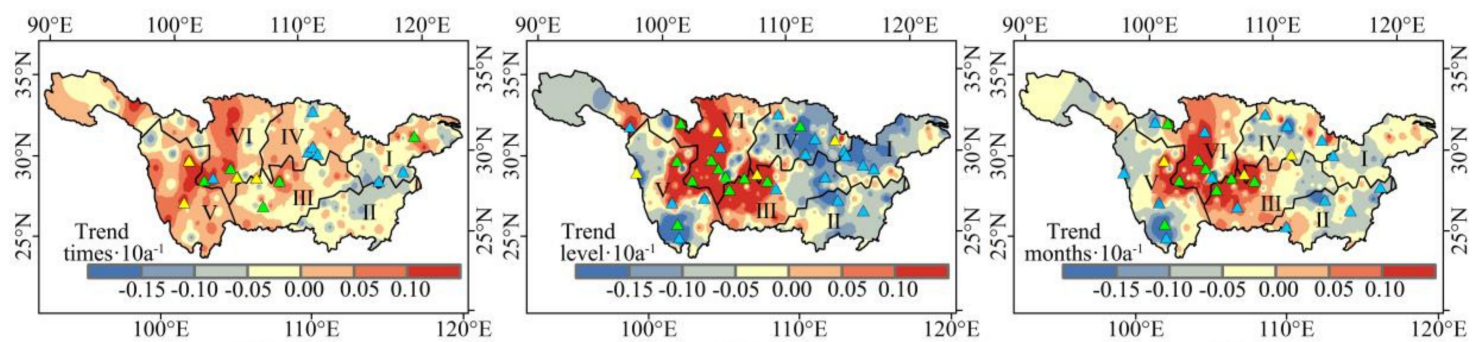

(a1)

(a2)
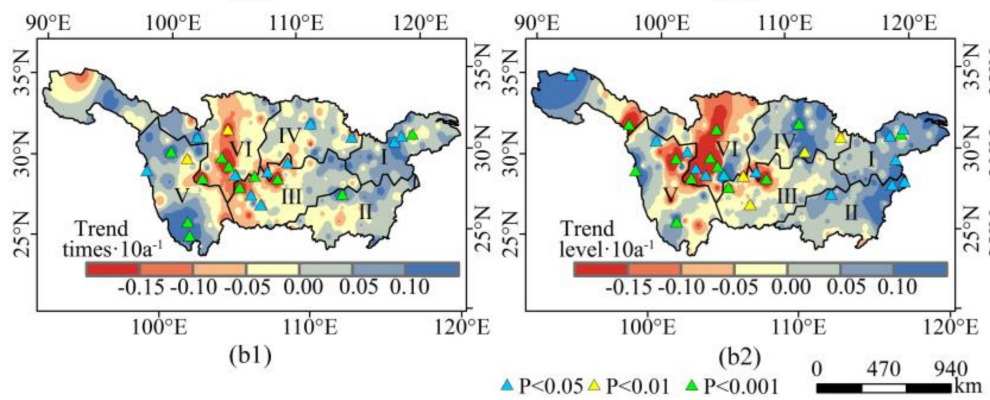

(a3)

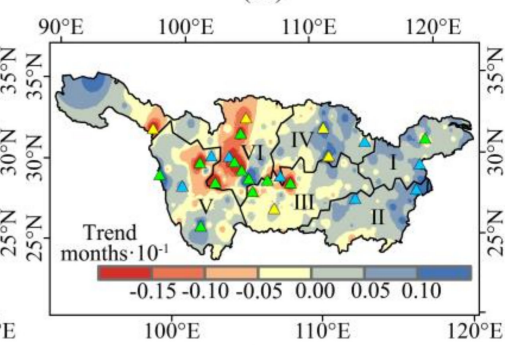

(b3)

Figure 7. The spatial distribution of linear trend of (a1) OTD from 1960 to 2017, (a2) DI from 1960 to 2017, (a3) DD from 1960 to 2017, (b1) OTW from 1960 to 2017, (b2) WI from 1960 to 2017, and (b3) WD from 1960 to 2017.

The drought and wetness events were divided into the first 29 years and the last 29 years for analysis. There were obvious differences in the changing tendency of drought and wetness events in some regions between 1960-1988 and 1989-2017, and there was a significant reversal in the changing tendency of drought and wetness events at the junction of subregions III, IV, and VI (Figure 8). The OTD, DI, and DD had changed from a significant decrease to a significant increase. In addition, DI had similar phenomena in the south of subregion I, the west of subregion II, and the east of subregion IV, reflecting that these regions were facing a higher risk of drought in the last 29 years (i.e., from 1989 to 2017). For the southern part of subregion V, the WI showed a significant increasing trend from 1960 to 1988 (Figure 9(a2)), while it showed a significant decreasing trend from 1989 to 2017 (Figure 9(b2)), reflecting that, although the overall DI in this region had decreased during the study period (Figure 7(a2)), it had been facing a higher risk of aridification in recent years.
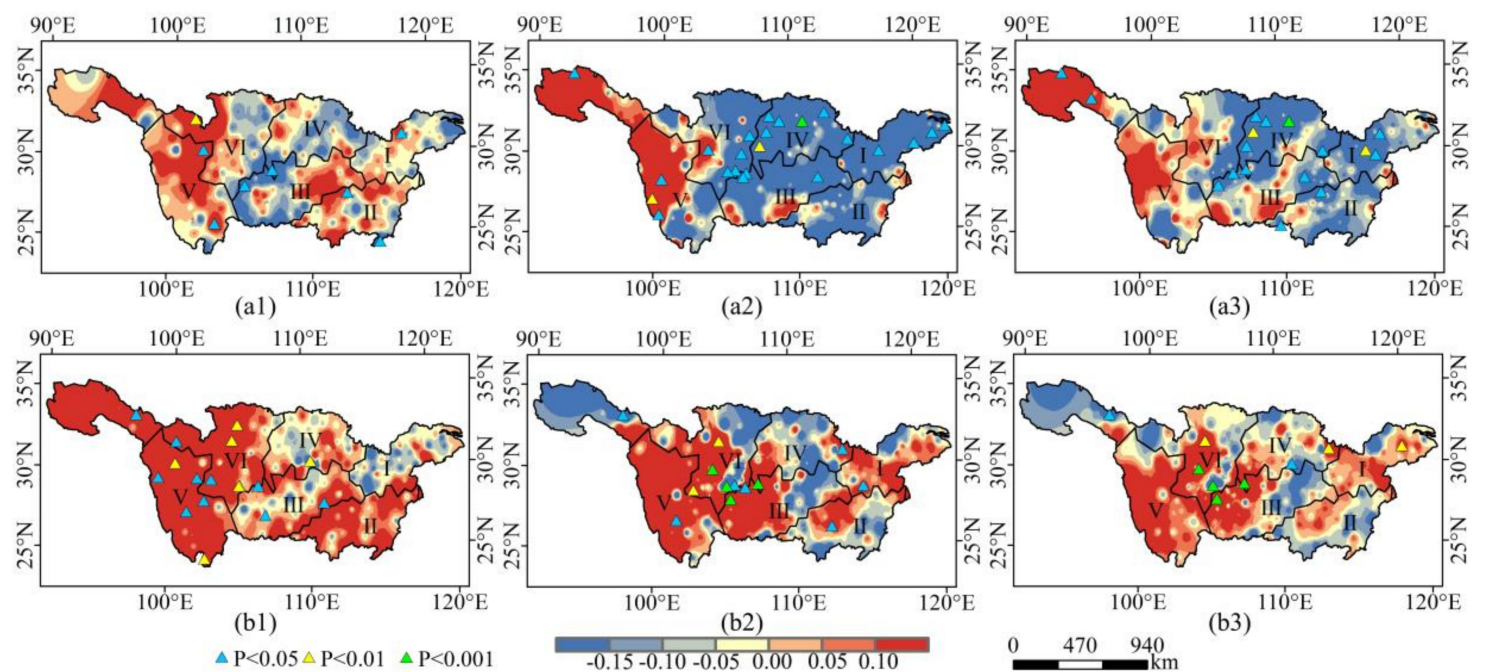

Figure 8. The spatial distribution of the linear trend of (a1) OTD from 1960 to 1988, (a2) DI from 1960 to 1988, (a3) DD from 1960 to 1988, (b1) OTD from 1989 to 2017, (b2) DI from 1989 to 2017, and (b3) DD from 1989 to 2017. 

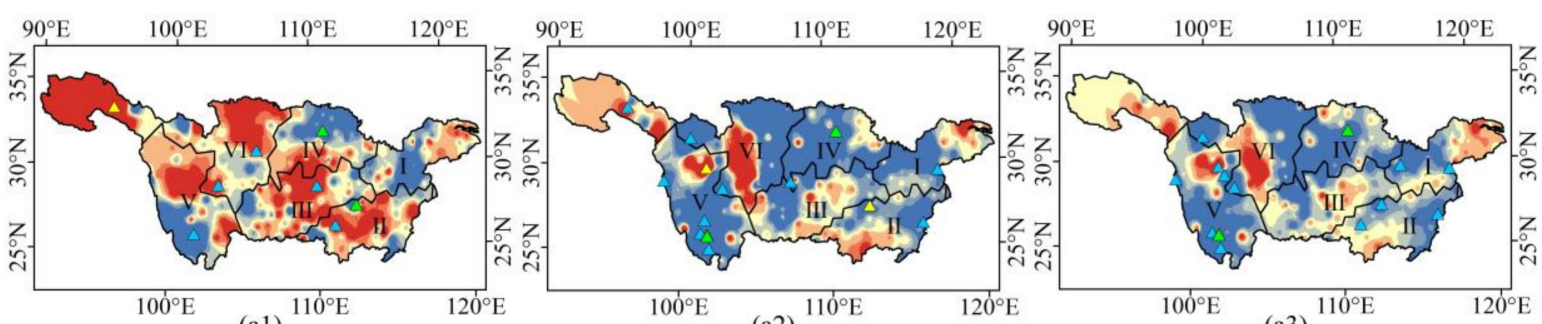

(a1)
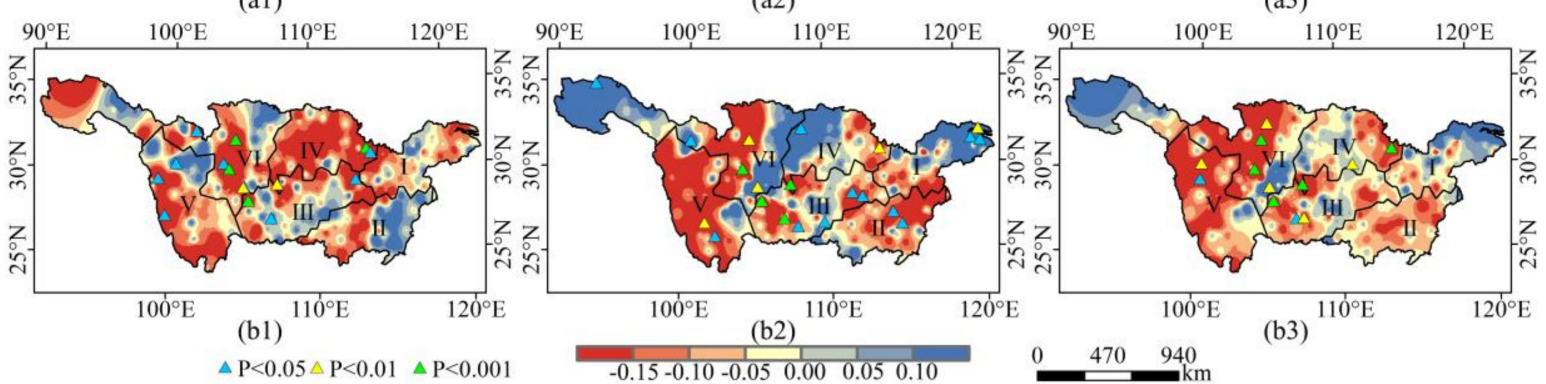

Figure 9. The spatial distribution of the linear trend of (a1) OTW from 1960 to 1988, (a2) WI from 1960 to 1988, (a3) WD from 1960 to 1988, (b1) OTW from 1989 to 2017, (b2) WI from 1989 to 2017, and (b3) WD from 1989 to 2017.

\subsubsection{Abrupt Changes and Variation Periods of Drought and Wetness}

The Mann-Kendall abrupt detection method was performed on the rotated principal component time series (RPCs) 1-6 to detect the drought and wetness abrupt years of each pattern (Figure 10). REOF6 experienced an abrupt change in 1994, which caused the trend of drought in subregion VI (Figure 10f, Figure 7). REOF1-REOF5 had undergone multiple abruptions, and the abrupt period was different for each. For abrupt years before 2000, REOF1 was 1977-1978, REOF2 was 1978-1983, REOF4 was 1964-1968, and REOF5 were 1961, 1966, and 1980; for abrupt years after 2000, REOF1 were 2001 and 2013, REOF2 was 1977-1978, REOF3 was 2000-2001, REOF4 were 2013, and REOF5 was 2017.

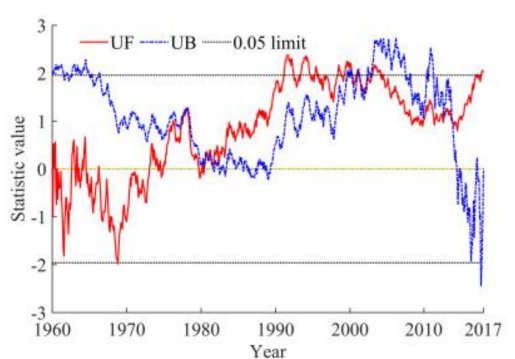

(a)

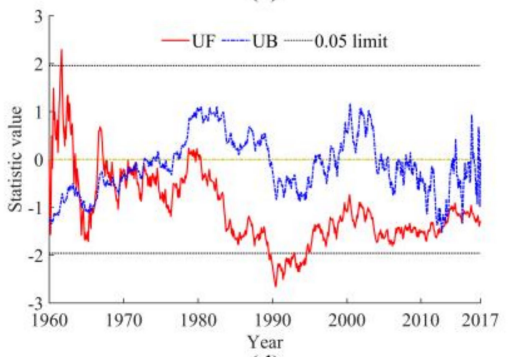

(d)

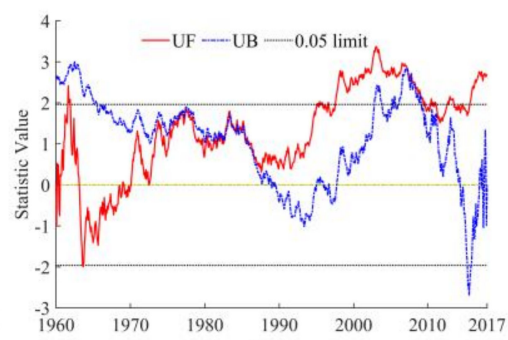

Year

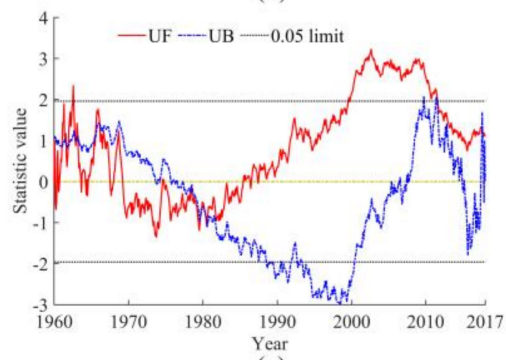

(e)

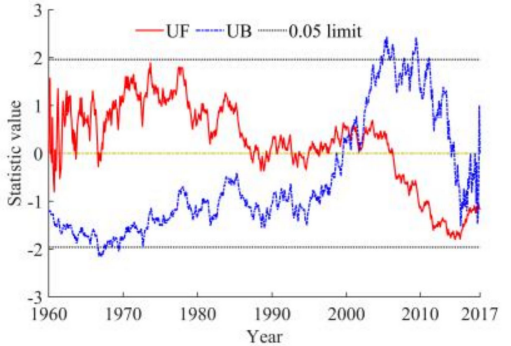

Year
$(c)$

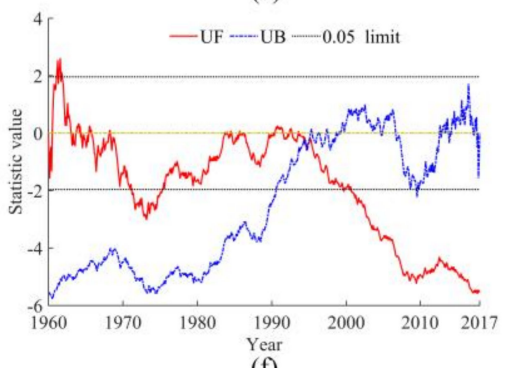

(f)

Figure 10. Abrupt change of (a) RPCs1, (b) RPCs2, (c) RPCs3, (d) RPCs4, (e) RPCs5, and (f) RPCs6.

The result of multiple abruptions is that the Yangtze River basin has experienced more drought and wetness transitions. The five-year moving average of SPEI values of the central load meteorological stations can reflect this situation (Figure 11). Among the six subregions of the Yangtze River basin, subregions IV-VI had a relatively long dry-wet transition period. The subregion IV was relatively 
dry before 1983, and changed to relatively wet after 1983 (Figure 11d). The subregion V had a relatively dry period from 1968 to 1989, and a relatively wet period from 1990 to 2009 (Figure 11e). The subregion VI was relatively wet before 1995 and relatively dry after 1995 (Figure 11f). Subregions I and II (Figure 11a,b) had undergone many dry-wet transitions, and the subregion III was in a long-term normal state before 1998 (Figure 11c). The abrupt change year of each of the RPCs had a good correspondence with the dry-wet conversion of the center load SPEI value of each subregion (Figure 10; Figure 11).
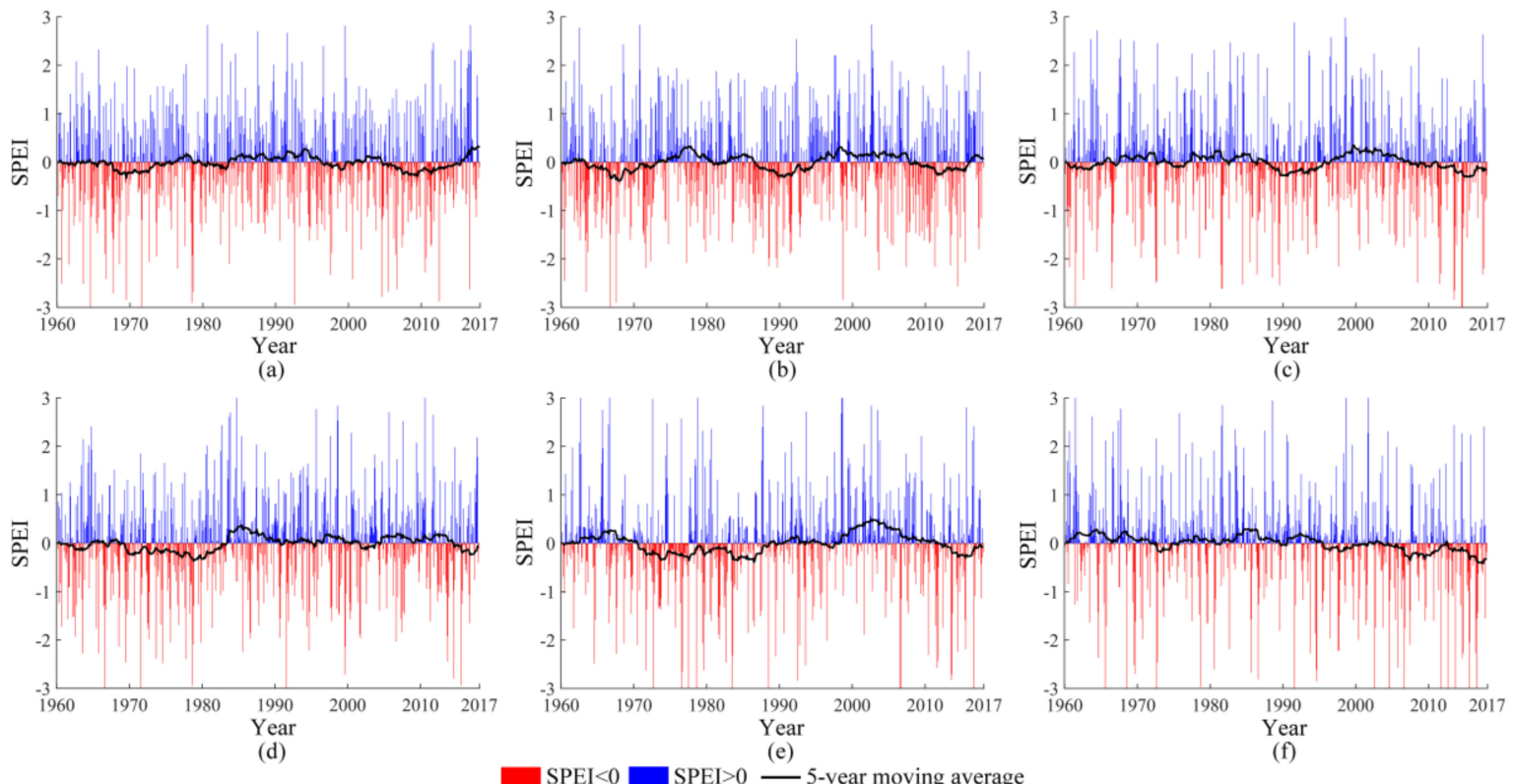

Figure 11. The 5-year moving average of central load SPEI of (a) subregion I, (b) subregion II, (c) subregion III, (d) subregion IV, (e) subregion V, and (f) subregion VI.

DI and WI are the most important indicators to describe the degree of drought and wetness in a region. Combining the periodic changes of DI and WI can better reflect the transition of drought and wetness in each subregion. Figure 12 shows that the DI of the subregions I-III, V, and VI had the first principal periods of 20,30,16,10, and 14 years, respectively, and the first principal period of DI in subregion IV was more than 30 years. In Figure 13, the WI had the first principal periods of 10, 7, 30, 9, 20, and 12 years, respectively. Only the principal periods of WI in the subregions III and V were longer than the principal periods of DI, and the principal periods of DI in the remaining subregions were longer than the principal periods of WI. 

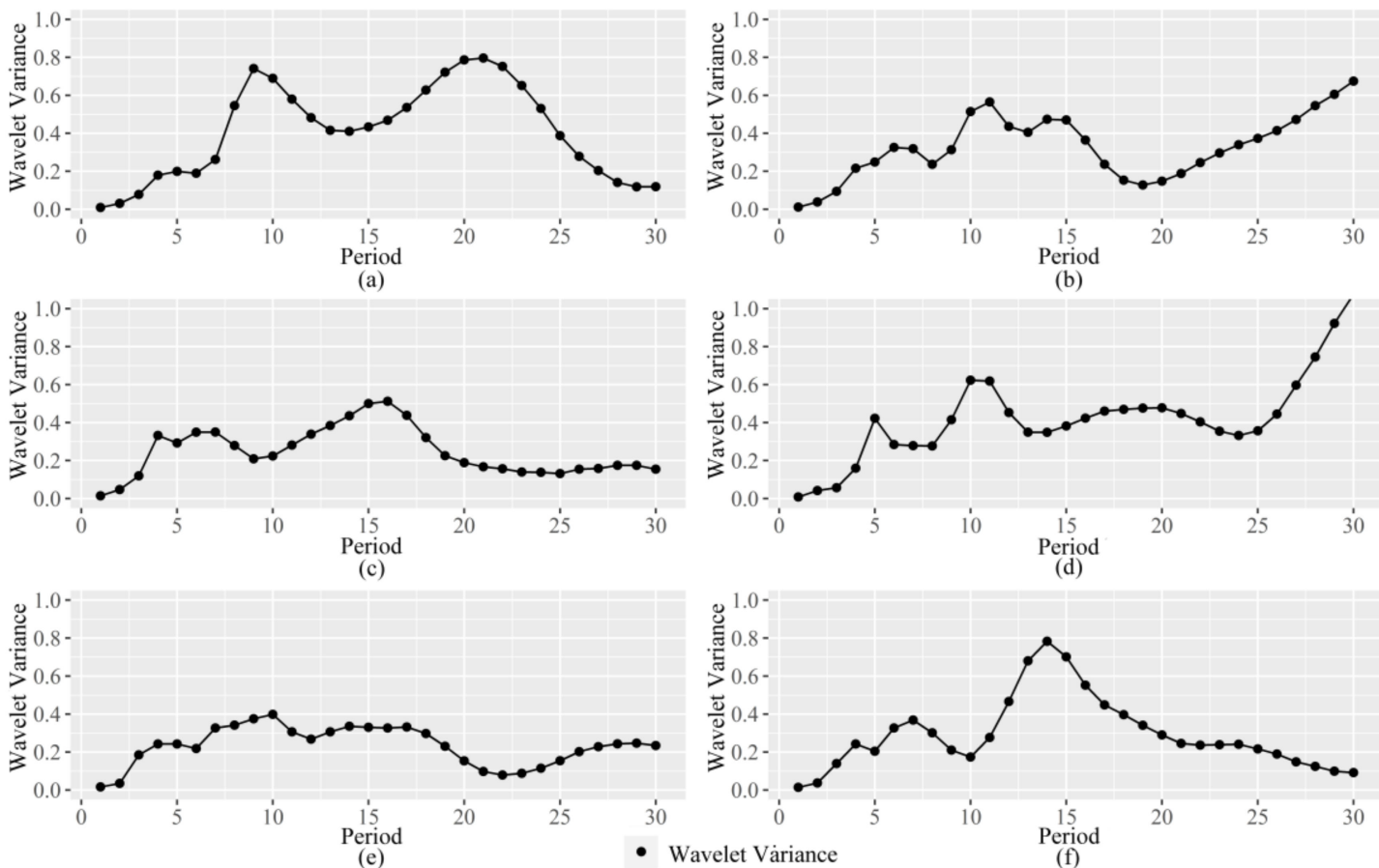

Figure 12. Morlet wavelet variance of DI in (a) subregion I, (b) subregion II, (c) subregion III, (d) subregion IV, (e) subregion V, and (f) subregion VI.

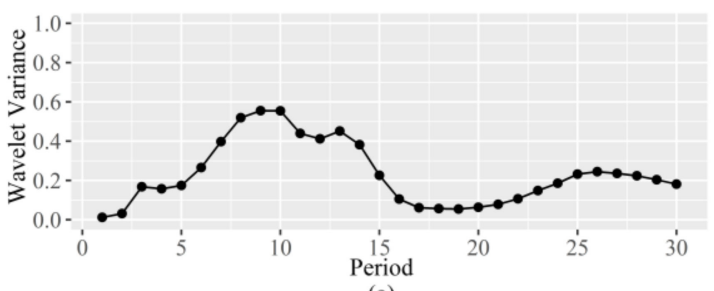

(a)
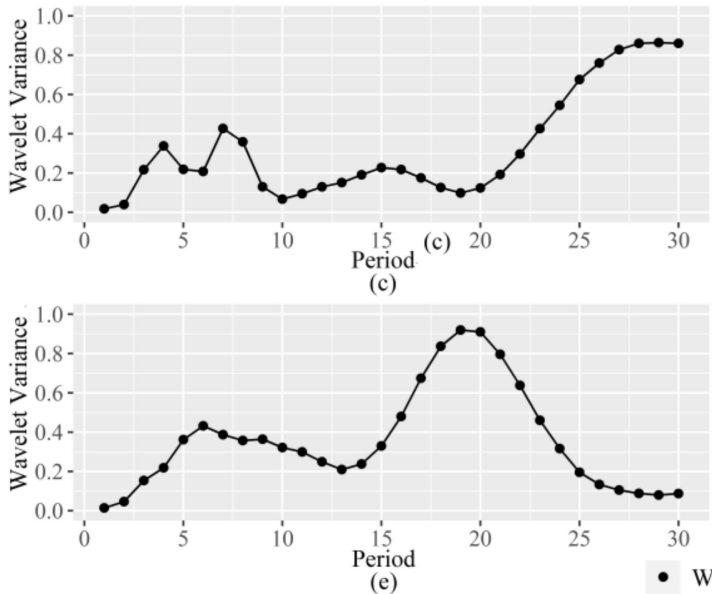

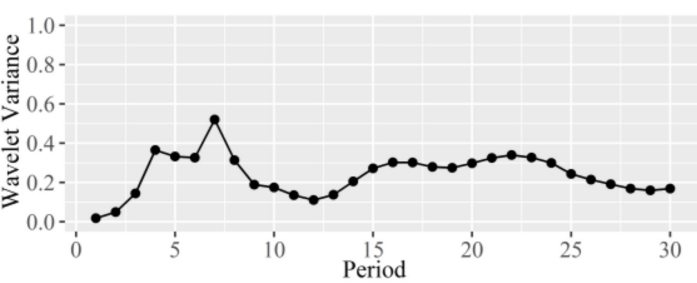

(b)
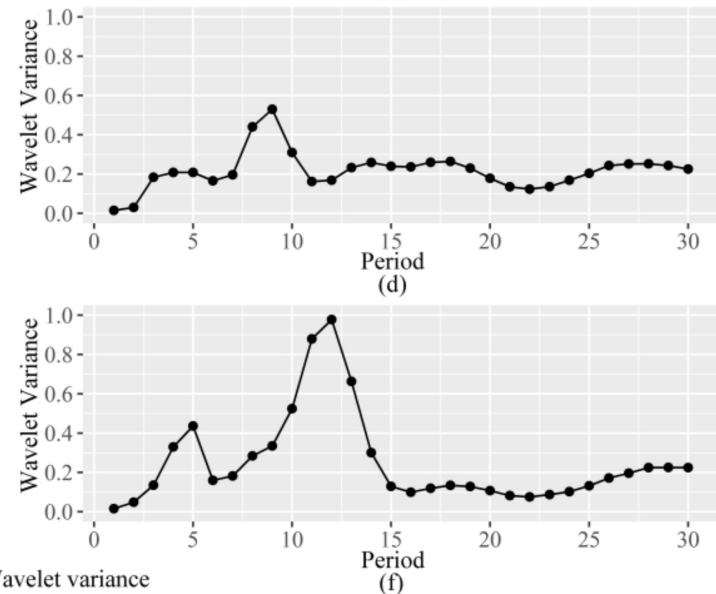

Figure 13. Morlet wavelet variance of WI in (a) subregion I, (b) subregion II, (c) subregion III, (d) subregion IV, (e) subregion V, and (f) subregion VI.

\section{Discussion}

\subsection{Effects of $A O$ and ENSO on Drought and Wetness}

The Yangtze River basin runs through the monsoon region of China, where climate change is affected by large-scale atmospheric ocean circulation, resulting in frequent and alternating droughts and floods. El Niño-southern oscillation (ENSO) is the most significant ocean-atmosphere coupling 
signal in the tropical Pacific. The warm and cold phases are represented by El Niño and La Niña events respectively [55,56]. ENSO affects every member of the East Asian monsoon system in the form of "tele-correlation" through atmospheric circulation, and thus indirectly affects the climate anomalies in China [57]. The change of Pacific sea temperature is strongly related to the spring and summer drought and flood disasters in the Yangtze River basin in China [58], therefore, ENSO has an important impact on changes to the drought and wetness in the Yangtze River basin. When the arctic oscillation (AO) is in the positive phase, the westerly wind belt over the mid-latitude Eurasian continent increases abnormally, leading to the weakening of the East Asian trough, which in turn causes the weakening of the meridional wind in the lower troposphere over East Asia. As a result, the underlying surface temperature increases and the East Asian winter monsoon weakens [59]. AO has an impact on the surface temperature, and the occurrence of climate anomalies in China and the Yangtze River basin in winter, spring, and summer [60,61].

The impact of ENSO and AO were analyzed through the generalized extreme value distribution (GEVD) of the OTD and OTW, and DI and WI in the Yangtze River basin, when the ENSO was in the cold and warm phases, and $\mathrm{AO}$ was in the positive and negative phases (Table 6). Figure 14 shows that in the warm phase of ENSO, there were slightly more OTD in the Yangtze River basin than in the cold phase, and slightly less OTW than in the cold phase. In the cold phase of ENSO, the DI was higher than that in the warm phase, and the WI was slightly less than that in the warm phase. In the positive phase of $\mathrm{AO}$, the probability of occurrence of OTD was almost the same as in the negative phase, but there were more OTW than in the negative phase. In the negative phase of AO, the DI and WI were slightly lower than in the positive phase. However, the influence of different phases of ENSO and $\mathrm{AO}$ on the duration of drought and wetness were less than the occurrence times and intensity, therefore, the probability distribution differences between DD and WD in different phases was small.

Table 6. ENSO warm (cold), AO positive (negative) phase year.

\begin{tabular}{|c|c|c|c|}
\hline Index & Phase & Criterion & Year \\
\hline \multirow{8}{*}{ ENSO } & \multirow{4}{*}{ Warm phase } & \multirow{4}{*}{$\geq 0.5^{\circ} \mathrm{C}$} & 19641966196919701973 \\
\hline & & & 19771978198019831987 \\
\hline & & & 19881992199519982003 \\
\hline & & & 2005200720102015 \\
\hline & \multirow{4}{*}{ Cold phase } & \multirow{4}{*}{$\leq-0.5^{\circ} \mathrm{C}$} & 19651968197119721974 \\
\hline & & & 19751976198419851989 \\
\hline & & & 19961997199920002001 \\
\hline & & & 2006200820092011 \\
\hline \multirow{10}{*}{$\mathrm{AO}$} & \multirow{4}{*}{ Positive phase } & \multirow{4}{*}{$\geq 0.2{ }^{\circ} \mathrm{C}$} & 19711972197419751983 \\
\hline & & & 19881989199019911992 \\
\hline & & & 19941998199920012006 \\
\hline & & & 20072008201120152017 \\
\hline & \multirow{6}{*}{ Negative phase } & \multirow{6}{*}{$\leq-0.2{ }^{\circ} \mathrm{C}$} & 19601962196319641965 \\
\hline & & & 19661967196819691970 \\
\hline & & & 19761977197819791981 \\
\hline & & & 19841985198619871993 \\
\hline & & & 19951997200020022003 \\
\hline & & & 200520092010 \\
\hline
\end{tabular}



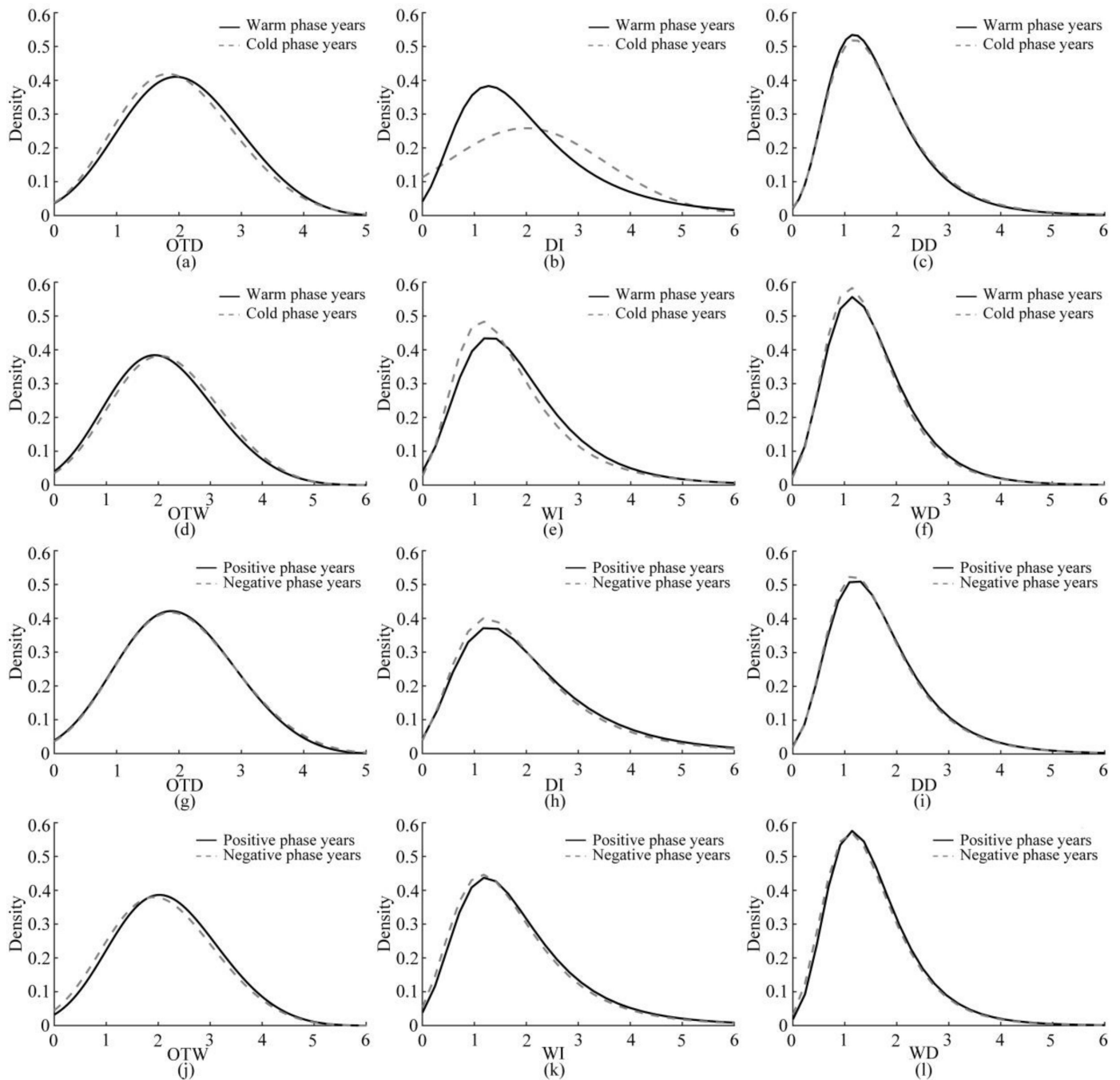

Figure 14. Generalized extreme value distribution (GEVD) of (a) OTD, (b) DI, (c) DD, (d) OTW, (e) WI, and (f) WD in different phase years of ENSO, and GEVD of (g) OTD, (h) DI, (i) DD, (j) OTW, (k) WI, and (1) WD in different phase years of AO.

\subsection{Continuity of Drought and Wetness Changes in the Yangtze River Basin}

Extreme climate events are important factors that triggers changes in regional drought and wetness. Extreme precipitation events have rapidly increased the degree of wetness in many areas, which can cause floods in severe cases. The Yangtze River basin, the Sichuan basin, and the middle and lower reaches of the Yangtze River are more likely to have extreme precipitation events, and are prone to high-risk flood disasters [62]. This study also shows that these two regions are frequent areas of extreme dry and wet months (Figure 2(e1,e2)). Although there are more extreme precipitation events in the Sichuan basin, due to its high concentration of annual precipitation [63], while prone to flooding, the southern part is still showing a trend of aridification (Figure $6(\mathrm{a} 1, \mathrm{~b} 1))$. In the middle and lower reaches of the Yangtze River, extreme precipitation has increased [62], and wetness events are also on the increase (Figure 6).

With the deepening of global warming, the increase in extreme high temperature events has led to an increase in evapotranspiration, which may lead to an increase in regional drought. Extreme high temperatures in the upper reaches of the Yangtze River have increased more significantly than that in the middle and lower reaches of the Yangtze River [64]; and the Sichuan basin, Yunnan-Guizhou Plateau, and other areas are closed high-temperature areas [29]. In southern China, where evapotranspiration is dominant [65], drought is likely to increase (Figure 6). 
The R/S analysis method is used to judge the trend continuity of the drought and wetness indicators in the Yangtze River basin. Table 7 showed that only a few hurst values are less than 0.5 , which are WI and WD of subregion II and subregion VI, and OTW of subregion IV respectively, indicating that the wetness conditions of these subregions are likely to change in the future. However, these hurst values were all greater than 0.38 , and the anti-persistence is not strong. The drought indicators are all persistent, indicating that the drought conditions in each subregion will basically maintain the current state, with the drought indicators in subregion $\mathrm{V}$ being the strongest among all subregions.

Table 7. Hurst values of the drought and wetness index.

\begin{tabular}{cccccccc}
\hline Type & Index & $\mathbf{5 8 3 4 5}$ & $\mathbf{5 7 8 9 6}$ & $\mathbf{5 7 7 3 1}$ & $\mathbf{5 7 1 5 4}$ & $\mathbf{5 6 3 5 7}$ & $\mathbf{5 6 1 9 6}$ \\
\hline \multirow{4}{*}{ Drought } & OTD & 0.51 & 0.57 & 0.57 & 0.70 & 0.87 & 0.67 \\
& DI & 0.66 & 0.61 & 0.55 & 0.53 & 0.67 & 0.63 \\
& DD & 0.65 & 0.59 & 0.50 & 0.55 & 0.69 & 0.58 \\
\hline \multirow{4}{*}{ Wetness } & OTW & 0.54 & 0.53 & 0.50 & $\mathbf{0 . 3 9}$ & 0.80 & 0.61 \\
& WI & 0.62 & $\mathbf{0 . 4 4}$ & 0.58 & 0.63 & 0.52 & $\mathbf{0 . 3 8}$ \\
& WD & 0.53 & $\mathbf{0 . 4 0}$ & 0.57 & 0.62 & 0.50 & $\mathbf{0 . 4 1}$ \\
\hline \multicolumn{7}{c}{ Note: Bold font means anti-persistence. }
\end{tabular}

\section{Conclusions}

In this study, the characteristics of dry and wet periods in The Yangtze River basin were analyzed, and the spatial distribution of the number of months of dryness/wetness of different magnitude was presented. REOF was used to find the subregions with different characteristics of dry and wet states in the Yangtze River basin. On this basis, the variance tendency of the OTD and OTW, the DD and WD, and the DI and WI in different subregions were analyzed. Finally, the combined analysis of the 5-year moving average of the SPEI value of the central load of each subregion, and the abrupt change of the RPCs, showed the dynamic change of the dry-wet transition in the Yangtze River Basin from 1960 to 2017. The main findings of this research are as follows:

(a) The Yangtze River basin is characterized by the coexistence of drought and flooding in the same areas. Areas where there were more dry/wet months at the same levels, are more likely to occur in the same region. There were more mildly and moderately dry months in the middle and lower reaches of the Yangtze River, but also mildly and moderately wet months. The upper reaches of the Yangtze River were prone to extremely dry months as well as extremely wet months.

(b) Using REOF to analyze the drought and wetness conditions of the Yangtze Riverb asin in time and space, it was found that there are six significant patterns in the Yangtze River basin. Through the "Take the minimum" method and the Tyson polygon, the Yangtze River basin can be divided into six characteristic subregions: east, southeast, south, north, southwest, and northwest.

(c) The distribution of SPEI values for the central load of each pattern from 1960 to 2017 shows that drought and wetness of a higher grade generally occur from May to September. The eastern parrern frequently changed between dry and wet status; the southeastern pattern had more normal periods of dry and wet; the southern pattern had higher levels of wet months; the northwestern pattern was consistent and relatively dry; the northern pattern and the southwestern pattern had a longer period of extreme drought/wetness in the 1970s and 1980s.

(d) From 1960 to 2017, the inter-annual change showed that the number of dry months, the OTD, and the DI and DD increased significantly in fewer subregions. However, spatially, the southern part of the Northwestern pattern and the western part of the southern pattern showed a significant decrease in the OTW, WI, and WD, and a significant increase in the OTD, DI, and DD, and this region changed from wetness to dryness in the past 29 years.

(e) According to the 5-year moving average of the central load SPEI value, the subregions I and II had experienced many dry-wet transitions, the subregion III had a long-term normal dry-wet state 
before 1998, and the subregions IV and VI had a relatively long dry-wet transition. However, these dry and wet state transitions can better correspond to the abrupt change of RPCs.

Author Contributions: Data curation, H.H.; formal analysis, H.H.; funding acquisition, B.Z.; investigation, Y.C.; methodology, H.H.; software, S.M.; validation, H.H.; writing—original draft, H.H. Writing—review and editing, H.H. All authors have read and agreed to the published version of the manuscript.

Funding: The study was financially supported by the National Natural Science Foundation of China (No. 41561024).

Conflicts of Interest: The authors declare no conflict of interest.

\section{Abbreviations}

SPEI: Standardized Precipitation Evapotranspiration Index; REOF, the Rotating Empirical Orthogonal function; RPCs, the rotated principal component time series; ENSO, the El Niño-Southern Oscillation; AO, the Arctic Oscillation; OTD, the occurrence times of drought events; OTW, the occurrence times of wetness events; DI, the drought intensity; WI, the wetness intensity; DD, the duration of drought events; WD, the duration of wetness events; GEVD, the generalized extreme value distribution; IDW, the inverse distance weight method.

\section{References}

1. Barlow, K.M.; Christy, B.P.; O'Leary, G.J.; Riffkin, P.A.; Nuttall, J.G. Simulating the impact of extreme heat and frost events on wheat crop production: A review. Field Crop. Res. 2015, 171, 109-119. [CrossRef]

2. El-Zein, A.; Tonmoy, F.N. Assessment of vulnerability to climate change using a multi-criteria outranking approach with application to heat stress in Sydney. Ecol. Indic. 2015, 48, 207-217. [CrossRef]

3. Huang, H.; Zhang, B.; Ma, S.; Ma, B.; Cui, Y.; Wang, X.; Ma, C.; Chen, K.; Zhang, T. Temporal and spatial variations of meteorological drought and drought risk analysis in Hedong Area of Gansu Province. Chin. J. Agrometeorol. 2020, 41, 459-469. [CrossRef]

4. Yang, T.; Lu, G.; Li, H.; He, H.; Wang, X. Advances in the study of projection of climate change impacts on hydrological extremes. Adv. Water Sci. 2011, 22, 279-286. [CrossRef]

5. Allen, M.R.; Ingram, W.J. Constraints on future changes in climate and the hydrologic cycle. Nature 2002, 419, 224-232. [CrossRef]

6. Rayne, S.; Forest, K. Evidence for increasingly variable Palmer Drought Severity Index in the United States since 1895. Sci. Total Environ. 2016, 544, 792-796. [CrossRef]

7. Ford, T.W.; Labosier, C.F. Meteorological conditions associated with the onset of flash drought in the Eastern United States. Agric. For. Meteorol. 2017, 247, 414-423. [CrossRef]

8. Salvati, L.; Sateriano, A.; Zitti, M. Long-term land cover changes and climate variations: A country-scale approach for a new policy target. Land Use Policy 2013, 30, 401-407. [CrossRef]

9. Plummer, N.; Salinger, M.J.; Nicholls, N.; Suppiah, R.; Hennessy, K.J.; Leighton, R.M.; Trewin, B.; Page, C.M.; Lough, J.M. Changes in Climate Extremes Over the Australian Region and New Zealand During the Twentieth Century. In Weather and Climate Extremes; Springer: Dordrecht, The Netherlands, 1999; pp. 183-202.

10. Lian, L.; Liu, B. Change characteristics of dry and wet spells in northwest China during the past 58 years. Arid Land Geogr. 2019, 42, 1301-1309. [CrossRef]

11. Shi, Y.; Shen, Y.; Li, D.; Zhang, G.; Ding, Y.; Hu, R.; Kang, E. Discussion on the present situation of climate change from warm-dry to warm-wet in Northwest China. Q. Sci. 2003, 23, 152-164.

12. Liu, L.; Zhai, P.; Zheng, Z. Variations in longest consecutive dry days in warm half year over Northern China. Acta Meteorol. Sin. 2008, 66, 474-477. [CrossRef]

13. Ni, S.; Gu, Y.; Peng, Y.; Liu, J.; Wang, H. Spatio-temporal pattern and evolution trend of drought disaster in China in recent seventy years. J. Nat. Disaster 2019, 28, 176-181. [CrossRef]

14. Yuan, X.; Wang, L.; Wu, P.; Ji, P.; Sheffield, J.; Zhang, M. Anthropogenic shift towards higher risk of flash drought over China. Nat. Commun. 2019, 10. [CrossRef] [PubMed]

15. Li, J.; Zhou, X.; Xu, Q. Analysis on storm-flood in Yangtze River in 2010 and influence of storage and discharge of Three Gorges Reservoir. Yangtze River 2011, 42, 1-5. [CrossRef]

16. Chen, X.; Zhou, B.; Zhong, H.; Liu, Y. Climate characteristic of the 2011 spring drought in the mid-lower Yangtze Basin. Resour. Environ. Yangtze Basin 2014, 23, 139-145. [CrossRef]

17. Yin, Z.; Liu, X.; Zhang, H. Analysis of storm flood occurred in Yangtze River Basin in July 2012. J. China Hydrol. 2014, 34, 81-87. [CrossRef] 
18. Lin, J.; Wang, W.; Cai, X. Analysis of the low-frequency oscillation characteristics over mid-lower reaches of the Yangtze River in 2011 and 2013 based on improved comprehensive meteorological drought index. J. Meteorol. Sci. 2016, 36, 810-818. [CrossRef]

19. Shan, L.; Zhang, L.; Zhang, Y.; She, D.; Xia, J. Characteristics of dry-wet abrupt alternation events in the middle and lower reaches of the Yangtze River Basin and their relationship with ENSO. J. Geogr. Sci. 2018, 28, 1039-1058. [CrossRef]

20. Wang, L.; Chen, W. Applicability Analysis of standardized precipitation evapotranspiration index in drought monitoring in China. Plateau Meteorol. 2014, 33, 423-431. [CrossRef]

21. Palmer, W.C. Meteorological Drought; US Department of Commerce, Weather Bureau: Washington, DC, USA, 1965; pp. 1-58.

22. McKee, T.B.; Doesken, N.J.; Kleist, J. The Relationship of Drought Frequency and Duration to Time Scales: Proceedings of Vulnerability; Cambridge University Press: Cambridge, UK, 1993; pp. 100-184.

23. Vicente-Serrano, S.M.; Beguería, S.; López-Moreno, J.I. A multiscalar drought index sensitive to global warming: The standardized precipitation evapotranspiration index. J. Clim. 2010, 23, 1696-1718. [CrossRef]

24. Zhang, S.; Zuo, H.; Ren, P.; Xiong, G.; Li, B.; Dong, W.; Wang, L. Application of standardized precipitation evapotranspiration index in China. Clim. Environ. Res. 2013, 18, 617-625.

25. Zhang, Q.; Tang, H.; Cui, F.; Dai, L. SPEI-based analysis of drought characteristics and trends in Hulun Buir grassland. Acta Ecol. Sin. 2019, 39, 7110-7123. [CrossRef]

26. Tang, M.; Zhang, B.; Zhang, Y.; Wang, G.; Ma, B.; Jia, Y. Assessment of spring and summer meteorological droughts based on SPEI and SPI in eastern agricultural region of Qinghai Province. J. Nat. Res. 2017, 32, 1029-1042. [CrossRef]

27. Liu, L.; Niu, Q.; Heng, J.; Li, H.; Xu, Z. Characteristics of dry and wet conversion and dynamic vegetation response in Yarlung Zangbo River basin. Trans. Chin. Soc. Agric. Eng. 2020, 36, 175-184. [CrossRef]

28. Zhang, D.; Hong, H.; Zhang, Q. Attribution of the changes in annual streamflow in the Yangtze River Basin over the past 146 years. Theor. Appl. Climatol. 2015, 119, 323-332. [CrossRef]

29. Ma, Q.; Xie, Z.; Chen, F. Temporal and spatial distribution of terrestrial water storage in the Yangtze River Basin during 1982-2005. Clim. Environ. Res. 2011, 16, 429-440. [CrossRef]

30. Liang, C.; Shen, S. Climatic features of the drought in the Yangtze River Basin and regions to its south disclosed by WAP index. J. Nanjing Univ. Nat. Sci. 2010, 2, 166-174. [CrossRef]

31. Allen, R.G.; Pereira, L.S.; Raes, D. Crop evapotranspiration: Guidelines for computing crop water requirements. In FAO Irrigation and Drainage Paper No. 56; FAO: Rome, Italy, 1998; pp. 1-15.

32. Ahmad, M.I.; Sinclair, C.D.; Werritty, A. Log-logistic flood frequency analysis. J. Hydrol. 1988, 98, $205-224$. [CrossRef]

33. Hosking, J.; Wallis, J. Regional Frequency Analysis-An Approach Based on L-Moments; Cambridge University Press: Cambridge, UK, 1997.

34. Chen, X.; Li, Y.; Yao, N.; Liu, D.; Javed, T.; Liu, C.; Liu, F. Impacts of multi-timescale SPEI and SWDI variations on winter wheat yields. Agric. Syst. 2020, 185, 102955. [CrossRef]

35. Gao, X.; Zhao, Q.; Zhao, X.; Wu, P.; Pan, W.; Gao, X.; Sun, M. Temporal and spatial evolution of the standardized precipitation evapotranspiration index (SPEI) in the Loess Plateau under climate change from 2001 to 2050. Sci. Total Environ. 2017, 595, 191-200. [CrossRef]

36. Soh, Y.; Koo, C.; Huang, Y.; Fung, K. Application of artificial intelligence models for the prediction of standardized precipitation evapotranspiration index (SPEI) at Langat River Basin, Malaysia. Comput. Electron. Agric. 2018, 144, 164-173. [CrossRef]

37. Wei, F. Modern Climate Statistics Diagnosis and Prediction Technology, 2nd ed.; China Meteorological Press: Beijing, China, 2007; pp. 63-65.

38. Denbo, D.W.; Allen, J.S. Rotary empirical orthogonal function analysis of currents near the Oregon Coast. J. Phys. Oceanogr. 1984, 14, 35-46. [CrossRef]

39. Wang, H.; Chen, Y.; Pan, Y.; Li, W. Spatial and temporal variability of drought in the arid region of China and its relationships to teleconnection indices. J. Hydrol. 2015, 523, 283-296. [CrossRef]

40. Zambreski, Z.; Lin, X.; Aiken, R.; Kluitenberg, G.; Pielke, R., Sr. Identification of hydroclimate subregions for seasonal drought monitoring in the U.S. Great Plains. J. Hydrol. 2018, 567, 570-581. [CrossRef]

41. Richman, M. Review article, rotation of principal components. J. Climatol. 1986, 6, 293-335. [CrossRef] 
42. Hannachi, A.; Jolliffe, I.; Stephenson, D. Empirical orthogonal functions and related techniques in atmospheric science: A review. Int. J. Climatol. 2007, 27, 1119-1152. [CrossRef]

43. Cai, Y.; Wu, T.; Zhang, W. Spatial and temporal distribution characteristics of heatwave in Sichuan Province based on REOF. J. Nat. Disaster 2018, 27, 201-208. [CrossRef]

44. Mann, H.B. Nonparametric Tests against Trend. Econometrica 1945, 13, 245-259. [CrossRef]

45. Kendall, K. Thin-film peeling-the elastic term. J. Phys. D Appl. Phys. 1975, 8, 1449-1452. [CrossRef]

46. Kendall, M.G. Rank Correlation Measures; Charles Griffin: London, UK, 1975; pp. 325-340.

47. Han, H.; Hou, J.; Huang, M.; Li, Z.; Xu, K.; Zhang, D.; Bai, G.; Wang, C. Impact of soil and water conservation measures and precipitation on streamflow in the middle and lower reaches of the Hulu River Basin, China. Catena 2020, 195, 104792. [CrossRef]

48. Yang, Y.; Tian, F. Abrupt change of runoff and its major driving factors in Haihe River Catchment, China. J. Hydrol. 2009, 374, 373-383. [CrossRef]

49. Mandelbrot, B.B. The Fractal Geometry of Nature; W.H. Freeman: New York, NY, USA, 1982; pp. $232-246$.

50. Gumbel, E.J. Statistical Theory of Extreme Values and Some Practical Applications; Applied Mathematics Series; U.S. National Bureau of Standards: Washington, DC, USA, 1954; Volume 33, p. 51.

51. Pearson, K. Notes on the history of correlation. Biometrika 1920, 13, 25-45. [CrossRef]

52. Cahill, A.T. Determination of changes in Streamflow Variance by means of a Wavelet-Based Test. Water Resour. Res. 2002, 38, 1-14. [CrossRef]

53. Watson, D.; Philip, G.M. A refinement of Inverse Distance Established interpolation. Geoprocesing 1985, 2, 315-327.

54. North, G.R.; Bell, T.L.; Cahalan, R.F.; Moeng, F.J. Sampling errors in the estimation of empirical orthogonal functions. Mon. Weather Rev. 1982, 110, 699-706. [CrossRef]

55. Yulaeva, E.; Wallace, J.M. The signature of ENSO in global temperature and precipitation fields derived from the microwave sounding unit. J. Clim. 1994, 7, 1719-1736. [CrossRef]

56. Yun, K.; Timmermann, A. Decadal Monsoon-ENSO relationships reexamined. Geophys. Res. Lett. 2018, 45, 2014-2021. [CrossRef]

57. Dutta, R.; Maity, R. Temporal evolution of hydroclimatic teleconnection and a time-varying model for long-lead prediction of Indian summer monsoon rainfall. Sci. Rep. 2018, 8, 10778. [CrossRef] [PubMed]

58. Zhang, Y.; Wu, M.; Li, D.; Liu, Y.; Li, S. Spatiotemporal decompositions of summer drought in China and Its teleconnection with global sea surface temperatures during 1901-2012. J. Clim. 2017, 30, 6391-6412. [CrossRef]

59. Gong, D.; Zhu, J.; Wang, S. A significant correlation between the summer precipitation in the Yangtze River basin and the early Arctic oscillation. Chin. Sci. Bull. 2002, 546-549. [CrossRef]

60. Gong, D.; Wang, S. Influence of Arctic Oscillation on winter climate over China. Acta Geol. Sin. 2003, 559-568. [CrossRef]

61. Ju, J.; Ren, J.; Lv, J. Effect of interdecadal variation of Arctic Oscillation on temperature increasing in North of East Asian Winter. Plateau Meteol. 2004, 429-434. [CrossRef]

62. Hu, S.; Zeng, W.; Wang, L.; He, X. Regional frequencies and spatio-temporal characteristics of extreme precipitation over Yangtze River Basin. Resour. Environ. Yangtze Basin 2019, 28, 2008-2018. [CrossRef]

63. Sun, H.; Zhang, X.; Li, Z.; Liu, F.; Shang, P.; Luo, Z.; Zhou, H. Inhomogeneity distribution of different types of precipitation in the Yangtze River Basin. Resour. Environ. Yangtze Basin 2019, 28, 1422-1433. [CrossRef]

64. Wang, Q.; Zhang, M.; Wang, S.; Luo, S.; Wang, B.; Zhu, X. Extreme temperature events in Yangtze River Basin during 1962-2011. Acta Geol. Sin. 2013, 68, 611-625. [CrossRef]

65. Ma, B.; Zhang, B.; Jia, L.; Huang, H. Conditional distribution selection for SPEI-daily and its revealed meteorological drought characteristics in China from 1961 to 2017. Atmos. Res. 2020. [CrossRef]

Publisher's Note: MDPI stays neutral with regard to jurisdictional claims in published maps and institutional affiliations. 